\title{
Optimal Fiscal and Monetary Policy When Money is Essential *
}

\author{
S. Borağan Aruoba ${ }^{\dagger}$ \\ University of Maryland
}

\author{
Sanjay K. Chugh ${ }^{\ddagger}$ \\ University of Maryland
}

First Draft: August 2006

This Draft: November 6, 2007

\begin{abstract}
We study optimal fiscal and monetary policy in an environment where explicit frictions give rise to valued money, making money essential in the sense that it expands the set of feasible trades. Our main results are in stark contrast to the prescriptions of earlier flexible-price Ramsey models. The two most important findings that emerge from our work are that the Friedman Rule is typically not optimal and inflation is very stable over time. Inflation is not a substitute instrument for a missing tax, as is sometimes the case in standard Ramsey models. Rather, the inflation tax is the natural tax to use because trades using money have rents associated with them. Regarding the optimal dynamic policy, realized (ex-post) inflation is quite stable over time, in contrast to the very volatile ex-post inflation rates that arise in standard flexibleprice Ramsey models. Taken together, these findings turn conventional wisdom from traditional Ramsey monetary models on its head.
\end{abstract}

Keywords: micro-founded models of money, Friedman Rule, inflation stability JEL Classification: E13, E52, E62, E63

${ }^{*}$ We thank Nancy Stokey, the editor and three anonymous referees for helpful comments. We also thank seminar participants at the Federal Reserve Board, Duke University, as well as participants at the 2006 Cleveland Fed Workshop on Money, Banking and Payments, the 2007 Philadelphia Workshop on Monetary and Macroeconomics, the Workshop on Optimal Monetary Policy and Central Bank Communication, the 2007 SCE Meetings (Montreal), the 2007 Econometric Society Summer Meetings (Duke University), the 2007 SED Meetings (Prague), and Stefania Albanesi, Christopher Waller and Randy Wright for helpful comments and discussions. The usual disclaimer applies.

${ }^{\dagger}$ E-mail address: aruoba@econ.umd.edu

${ }^{\ddagger}$ E-mail address: chughs@econ.umd.edu 


\section{Contents}

1 Introduction $\quad 3$

2 Model $\quad 5$

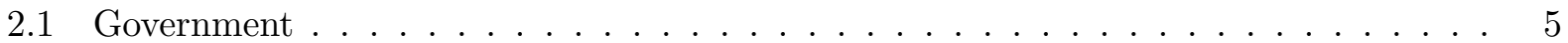

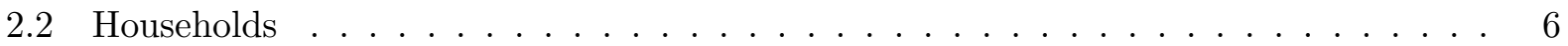

2.2.1 Household CM Problem . . . . . . . . . . . . . . . . . . 6

2.2.2 Household DM Problem . . . . . . . . . . . . . . . . . . . 7

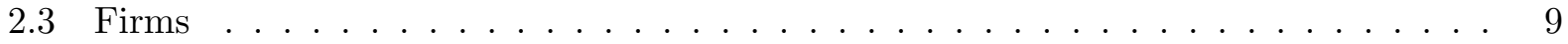

2.4 Private-Sector Equilibrium $\ldots \ldots \ldots \ldots \ldots \ldots$

3 Ramsey Problem $\quad 10$

4 Optimal Policy 11

4.1 Optimal Deviation from the Friedman Rule . . . . . . . . . . . . . . . . . 12

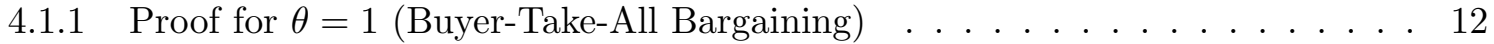

4.1 .2 Numerical Results . . . . . . . . . . . . . . . . . . . . . . . . . 14

4.2 Optimal Inflation Stability . . . . . . . . . . . . . . . . . . 15

5 Discussion $\quad 18$

5.1 Optimal Deviation from the Friedman Rule . . . . . . . . . . . . . . . . . . 19

$5.1 .1 \quad$ Alternative Instruments in the DM . . . . . . . . . . . . . . . . . 19

5.1 .2 Alternative Instruments in the CM . . . . . . . . . . . . . . . . . 20

5.1 .3 Comparison of Results with CCK . . . . . . . . . . . . . . . . . 21

5.1 .4 Rents Associated with DM Activity . . . . . . . . . . . . . . . 22

5.1 .5 Alternative Model Specifications . . . . . . . . . . . . . . . . . . 23

5.2 Optimal Inflation Stability . . . . . . . . . . . . . . . . 23

5.2 .1 Relative Price Distortions . . . . . . . . . . . . . . . . . . . 23

5.2 .2 Dissipation of Exogenous Volatility . . . . . . . . . . . . . . . . 24

6 Conclusion $\quad 26$

A The Ramsey Problem $\quad 28$

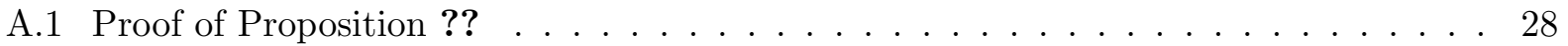

A.2 The Solution to the Ramsey Problem . . . . . . . . . . . . . . . . . 30 


\section{Introduction}

Monetary theory has made important advances of late, ones that enable researchers interested in applied policy questions to consider explicit frictions that give rise to valued money. In this paper, we build on the work of Lagos and Wright (2005) to study optimal fiscal and monetary policy, in the tradition of Lucas and Stokey (1983) and Chari, Christiano, and Kehoe (1991). Two important findings emerge from our work, both of which are opposite those of earlier flexible-price Ramsey monetary models: the Friedman Rule is typically not optimal and inflation volatility is low in the face of business-cycle magnitude shocks. Our results thus turn conventional wisdom from standard Ramsey monetary models on its head.

The contribution of Lagos and Wright (2005) - hereafter, LW — was to integrate search-based monetary theory, in the spirit of Kiyotaki and Wright (1989, 1993), with standard dynamic general equilibrium macroeconomics. This integration makes the study of policy questions much easier and potentially more relevant than in earlier search-based models. However, these models have been criticized on two grounds. First, they superficially resemble standard cash-in-advance (CIA) or money-in-the-utility-function (MIU) models, making some question whether they really are any deeper than reduced-form models of money. This point has been raised by, among others, Howitt (2003). Second, until now, the policy questions addressed in these new models have been largely confined to the deterministic welfare costs of inflation. When parameterized to seem as close as possible to standard CIA and MIU models, the quantitative answers they have yielded to this question are similar to those obtained with CIA and MIU models, further adding to the sense that these new models simply re-invent CIA or MIU. In this paper, we ask a different policy-relevant question in these new models, and even when we parameterize the model to look very similar to standard reduced-form models of money, we reach conclusions very different from those reached by Chari, Christiano, and Kehoe (1991) and others using typical CIA and MIU frameworks. Our results thus show that the answers to policy questions may indeed be very different once monetary frictions are treated seriously.

We study the canonical Ramsey problem of optimal fiscal and monetary policy using the LW model. Our first main finding is that the nominal interest rate is typically positive because it is optimal to tax activities that require cash. ${ }^{1}$ This optimal deviation from the Friedman Rule is not because the inflation tax acts as a substitute instrument for a missing tax, as is sometimes

\footnotetext{
${ }^{1}$ In a different context, one that abstracts from public finance considerations, Rocheteau and Wright (2005) show that a positive nominal interest rate may be optimal because it can correct inefficiencies along the extensive margin of bilateral trading by influencing the relative number of traders on each side of the market. In other micro-founded models of money that also abstract from public finance considerations, Shi (1997), Bhattacharya, Haslag, and Martin (2005), and Head and Kumar (2005) also find that deviations from the Friedman Rule can be optimal.
} 
the case in Ramsey models. That is, taxation of activities that require cash does not arise because of incompleteness of the tax system we consider. Rather, because all final goods should be taxed to some degree as part of an optimal tax system, taxation of cash activities is naturally part of the second-best allocation. This prescription is simply standard Ramsey theory. In the LW environment, the explicit spatial and informational frictions that make money essential (in Kocherlakota's (1998) sense that it expands the set of feasible trades) render inflation the most natural way of taxing activities that require money. Such a prescription does not arise in Chari, Christiano, and Kehoe (1991) - hereafter, CCK - because taxation of labor income indirectly taxes cash activities, making the inflation tax unnecessary in their environment. As we discuss, our results can be reconciled both technically and conceptually with those of CCK. Interestingly, Kocherlakota (2005) conjectured that the Friedman Rule may not be optimal in a Ramsey problem in search-based models. Our results show his conjecture is correct.

Our second main finding is that realized (ex-post) inflation is quite stable over time in the face of shocks, which is in contrast to the very volatile ex-post inflation rates that CCK find. Inflation volatility is high in CCK and the related literature because surprise movements in the price level allow the government to synthesize real state-contingent debt payments from nominally risk-free government bonds, without distorting the relative prices of consumption goods. The government then need not change other, distortionary, tax rates much in response to shocks. In our model, in contrast, real activity is distorted by inflation because inflation affects relative prices of goods, in a way that a flexible-price CIA or MIU model cannot articulate. The welfare cost of this relative-price distortion dominates the insurance value of generating state-contingent debt in our model, rendering inflation very stable. The frictions underlying monetary trade thus provide novel justification for the optimality of inflation stability, a prescription that resonates with most central bankers. This result also echoes the long-standing idea in monetary economics that inflation variability is undesirable because it induces relative price shifts and demonstrates that nominal rigidities are not a necessary feature of such a mechanism.

An important technical advantage of the LW framework is that the distribution of moneyholdings across agents is simple to track: it simply collapses periodically to a point. At the expense of a heavier computational burden, one may want to think about optimal fiscal and monetary policy when this distribution is non-trivial. Once one goes down that route, an interesting taxation framework to apply may be the Mirrleesian one, in which idiosyncratic shocks and private information become important considerations in shaping optimal policy. However, because even the simpler step of characterizing the Ramsey-optimal policy, which assumes a representative agent, has not been studied in this class of models, we think it makes sense to begin here.

The rest of the paper is organized as follows. Section 2 lays out the baseline LW model in which 
we study optimal policy. Section 3 presents the Ramsey problem. In Section 4, we characterize the optimal policy. Included here is a proof for a particularly important version of the model in which the Friedman Rule is not optimal, followed by quantitative results that demonstrate that Ramsey-optimal inflation in the face of business cycle shocks is at least an order of magnitude more stable than benchmark Ramsey results. Section 5 provides discussion and interpretation of our results. Section 6 summarizes and offers ideas for future work.

\section{Model}

We establish our results in a version of the LW model. In this model, the agents in the economy participate in a centralized market $(\mathrm{CM})$ where they trade general consumption goods and assets with the market and in a decentralized market (DM) where they trade specialized consumption goods bilaterally. To enhance comparability with the benchmark cash-credit environment used by CCK, we alter slightly the timing of markets in the original LW model. Specifically, in our version, the $\mathrm{CM}$ is the first market in a given period, followed by the DM. We make this alteration because we would like asset markets (which in the LW model meet in the CM) to convene in any period before goods markets (in particular, before goods markets in which money must be used for transactions), which is the timing assumed by CCK. However, we do not see how any of our results depend on the temporal ordering of markets within a period. We proceed by describing the activities of the government, households, and firms in our model.

\subsection{Government}

Government consumption is assumed to be composed entirely of goods produced in the CM. In nominal terms, the flow budget constraint of the government is

$$
M_{t}+B_{t}+P_{t} w_{t} \tau_{t}^{h} H_{t}=P_{t} G_{t}+M_{t-1}+R_{t-1} B_{t-1},
$$

which states that the government has three sources of revenues to pay for its consumption: labor income tax revenues, nominal money creation, and nominal debt issuance. The notation is standard: $M_{t}$ denotes nominal money outstanding at the end of period $t, B_{t}$ is nominally risk-free government

debt outstanding at the end of period $t, R_{t}$ is the gross nominal interest rate on bonds, $\tau_{t}^{h}$ is a proportional labor income tax on aggregate hours worked $H_{t}$ in the $\mathrm{CM}, P_{t}$ is the nominal price level in the CM, and $w_{t}$ is the real wage in the CM. The nominal return $R_{t}$ is known at the time $B_{t}$ is issued and paid in the CM of period $t+1$. We assume that bonds are simply book entries with no tangible proof that one can carry around. 


\subsection{Households}

Households periodically transact in markets for general goods and assets (the CM) and in markets for specialized goods (the DM). In the DM, money is essential in the sense that transactions there are infeasible without money. ${ }^{2}$ In the CM, because markets are Walrasian trades can proceed with or without money. We describe first the timing of events in a given period and then present the household's CM and DM problems.

Events unfold for a household in a given period $t$ as follows:

- The household begins the CM with portfolio $m_{t-1}$ and $b_{t-1}$.

- The uncertainty for the current period is resolved, and the household observes government consumption $G_{t}$ and the level of technology $Z_{t}$. We denote the aggregate state collectively by $S_{t}$.

- The household receives the receipts from bond holdings, $R_{t-1} b_{t-1}$.

- The household chooses its CM consumption $x_{t}$, labor supply $h_{t}$, portfolio $\left(m_{t}, b_{t}\right)$ and pays the labor income tax.

- The household enters the DM with $m_{t}$.

- Depending on the household's trade in the DM, it exits the DM with $m_{t}-d_{t}, m_{t}+d_{t}$, or $m_{t}$ money holdings, where $d_{t}$ is the buyer's payment in bilateral trade.

\subsubsection{Household CM Problem}

For a household that enters the CM with money holdings $m_{t-1}$ and bond holdings $b_{t-1}$, the CM problem is

$$
W_{t}\left(m_{t-1}, b_{t-1}, S_{t}\right)=\max _{x_{t}, h_{t}, m_{t}, b_{t}}\left\{U\left(x_{t}\right)-A h_{t}+V_{t}\left(m_{t}, b_{t}, S_{t}\right)\right\}
$$

subject to

$$
P_{t} x_{t}+m_{t}+b_{t}=P_{t} w_{t}\left(1-\tau_{t}^{h}\right) h_{t}+m_{t-1}+R_{t-1} b_{t-1},
$$

where $W_{t}($.$) denotes the value of entering the CM and V_{t}($.$) denotes the value of entering the DM$ that convenes after the CM in period $t$. Note that instantaneous utility in the CM is separable and linear in labor; it is this quasi-linearity in preferences that makes the LW model so tractable because it guarantees a degenerate distribution of money holdings across households after the conclusion of each CM.

\footnotetext{
${ }^{2}$ In a more general model, one can allow a double-coincidence meeting where barter takes place. Doing so does not change any of the properties of the current model and we abstract from it.
} 
Eliminating $h_{t}$ in the objective function using the budget constraint, the first-order conditions with respect to $x_{t}, m_{t}$, and $b_{t}$ are

$$
\begin{gathered}
U^{\prime}\left(x_{t}\right)=\frac{A}{w_{t}\left(1-\tau_{t}^{h}\right)}, \\
\frac{A}{P_{t} w_{t}\left(1-\tau_{t}^{h}\right)}=V_{m, t}\left(m_{t}, b_{t}, S_{t}\right), \\
\frac{A}{P_{t} w_{t}\left(1-\tau_{t}^{h}\right)}=V_{b, t}\left(m_{t}, b_{t}, S_{t}\right),
\end{gathered}
$$

familiar from LW. These optimality conditions imply the usual LW results about degeneracy of asset holdings $\left(m_{t}, b_{t}\right)$ across households because they are independent of $\left(m_{t-1}, b_{t-1}\right) .{ }^{3}$ All households choose the same portfolio at the end of the CM regardless of the portfolio they entered the market with. Thus, the LW result of degeneracy of money holdings readily extends to bond holdings as well. Moreover, we have standard envelope conditions

$$
\begin{aligned}
& W_{m, t}\left(m_{t-1}, b_{t-1}, S_{t}\right)=\frac{A}{P_{t} w_{t}\left(1-\tau_{t}^{h}\right)}, \\
& W_{b, t}\left(m_{t-1}, b_{t-1}, S_{t}\right)=\frac{A R_{t-1}}{P_{t} w_{t}\left(1-\tau_{t}^{h}\right)},
\end{aligned}
$$

which show $W_{t}($.$) is linear in its arguments. In our derivations below, we use$ $\chi_{t} \equiv E_{t}\left[A /\left\{P_{t+1} w_{t+1}\left(1-\tau_{t+1}^{h}\right)\right\}\right]$ which is the marginal value of entering $t+1$ with one extra unit of money.

\subsubsection{Household DM Problem}

Now we turn to the household's DM problem. Knowing that the distribution of money holdings is degenerate in equilibrium, we will, for notational simplicity, write the household DM problem assuming that when it meets a trading partner, the trading partner has equilibrium money holdings $M_{t}$; this allows us to conserve on integrating over all possible money holdings of trading partners that a given household could meet. With probability $\sigma$, the household is a buyer in the DM; with probability $\sigma$, the household is a seller in the DM; and with probability $1-2 \sigma$, the household does not participate in the $\mathrm{DM}$ and continues to the $\mathrm{CM}$ of the next period without transacting. ${ }^{4}$

\footnotetext{
${ }^{3}$ This result requires a small qualification for bond holdings. There are two parts of the argument in LW. The first part relies on the observation that $\left(m_{t-1}, b_{t-1}\right)$ does not appear in $(3)$ and $(4)$. The second part relies on the strict concavity of $V($.$) or, more specifically, the strict monotonicity of V_{m}($.$) and V_{b}($.$) which means the choice of m_{t}$ and $b_{t}$ is unique. Both parts of the argument go through for money in our environment but only the first part goes through for bonds. This means that in principle there could be multiple values of $b_{t}$ that households choose, which can create a distribution of bond holdings. Fortunately, such a distribution of bonds holdings is not important for any of our results because bond-holdings will not affect the bargaining problem, as we show below.

${ }^{4}$ This setup can be justified by either the search framework of the original LW model or the preference shocks setup of AWW.
} 
Buyers consume $q$ in the DM, experiencing utility $u(q)$; sellers produce $q$ in the DM, experiencing disutility, which can be interpreted as the cost of production, $c(q, Z)$, where $c_{Z}<0$. We assume throughout our basic model that $c(q, Z)=q / Z .^{5}$

We can write the problem of a household that enters the DM with portfolio $\left(m_{t}, b_{t}\right)$ as

$$
\begin{aligned}
V_{t}\left(m_{t}, b_{t}, S_{t}\right) & =\sigma\left\{u\left[q\left(m_{t}, M_{t}, S_{t}\right)\right]+\beta E_{t} W_{t+1}\left[m_{t}-d\left(m_{t}, M_{t}, S_{t}\right), b_{t}, S_{t+1}\right]\right\} \\
& +\sigma\left\{-c\left[q\left(M_{t}, m_{t}, S_{t}\right), Z_{t}\right]+\beta E_{t} W_{t+1}\left[m_{t}+d\left(M_{t}, m_{t}, S_{t}\right), b_{t}, S_{t+1}\right]\right\} \\
& +(1-2 \sigma) \beta E_{t} W_{t+1}\left(m_{t}, b_{t}, S_{t+1}\right) .
\end{aligned}
$$

The quantity $q\left(m_{b t}, m_{s t}, S_{t}\right)$ is the quantity produced and exchanged in a bilateral meeting in the DM, where $m_{b}$ denotes the money holdings of the buyer, $m_{s}$ denotes the money holdings of the seller, and $d\left(m_{b}, m_{s t}, S_{t}\right)$ is the amount of money that changes hands. We refer to $[q(),. d()$.$] as the$ terms of trade in a single-coincidence meeting. Note that due to the nature of the bonds, neither the buyer's nor the seller's bond holdings will matter for $q$ and $d$.

In the DM, we must specify the protocol by which the price and quantity in any bilateral trade are determined - that is, we must define the structure by which the terms of trade are determined. We choose generalized Nash bargaining problem with the bargaining power of buyer given by $\theta$. Denoting the portfolio of the buyer by $\left(m_{t}, b_{t}\right)$, that of the seller by $\left(\tilde{m}_{t}, \tilde{b}_{t}\right)$, the generalized Nash bargaining problem is

$$
\begin{gathered}
\max _{q_{t}, d_{t}}\left[u\left(q_{t}\right)+\beta E_{t} W_{t+1}\left(m_{t}-d_{t}, b_{t}, S_{t+1}\right)-\beta E_{t} W_{t+1}\left(m_{t}, b_{t}, S_{t+1}\right)\right]^{\theta} \\
\times\left[-c\left(q_{t}, Z_{t}\right)+\beta E_{t} W_{t+1}\left(\tilde{m}_{t}+d_{t}, \tilde{b}_{t}, S_{t+1}\right)-\beta E_{t} W_{t+1}\left(\tilde{m}_{t}, \tilde{b}_{t}, S_{t+1}\right)\right]^{1-\theta}
\end{gathered}
$$

subject to

$$
d_{t} \leq m_{t}
$$

where (7) is simply a feasibility condition stating the buyer cannot spend more than he has and the threat points are the values of continuing on to the next $\mathrm{CM}$ in period $t+1$. Using the envelope condition (5) and the definition of $\chi_{t}$

$$
\max _{q_{t}, d_{t}}\left\{u\left(q_{t}\right)-\beta d_{t} \chi_{t}\right\}^{\theta}\left\{-c\left(q_{t}, Z_{t}\right)+\beta d_{t} \chi_{t}\right\}^{1-\theta}
$$

subject to (7). In equilibrium, one can show, as LW do, (7) binds and the quantity produced solves

$$
\beta \chi_{t} m_{t}=g\left(q_{t}, Z_{t}\right)
$$

\footnotetext{
${ }^{5}$ This functional form can be obtained by assuming a linear production function in effort, $q=Z e$, and a linear disutility of effort, $-e$, which is just a normalization. Inverting the production function and substituting into the disutility function gives the cost function $c(q, Z)=q / Z$.
} 
where

$$
g(q, Z) \equiv \frac{\theta c(q, Z) u^{\prime}(q)+(1-\theta) u(q) c_{q}(q, Z)}{\theta u^{\prime}(q)+(1-\theta) c_{q}(q, Z)}
$$

as in LW. The efficient quantity in this bilateral meeting is given by $q^{*}\left(Z_{t}\right)$ which solves $u^{\prime}(q)=$ $c_{q}(q, Z)$. It remains to be seen whether or not the Ramsey equilibrium will feature $q=q^{*}$. Because the expectation in $\chi_{t}$ is taken with respect to $S_{t}$, we denote the bargaining problem outcomes as $q\left(m_{t}, S_{t}\right)$ and $d\left(m_{t}, S_{t}\right)$, where the first argument is understood to be the money holdings of the buyer. Substituting this solution into the DM problem (6) and using the envelope conditions for $W_{t}($.$) , we get$

$$
V_{t}\left(m_{t}, b_{t}, S_{t}\right)=\sigma\left\{u\left[q_{t}\left(m_{t}, S_{t}\right)\right]-c\left[q\left(M_{t}, S_{t}\right), Z_{t}\right]-\beta \chi_{t} m_{t}+\beta \chi_{t} M_{t}\right\}+\beta E_{t} W_{t+1}\left(m_{t}, b_{t}, S_{t+1}\right)
$$

The relevant envelope conditions for $V_{t}($.$) are$

$$
\begin{gathered}
V_{m, t}\left(m_{t}, b_{t}, S_{t}\right)=\beta \chi_{t}\left[\sigma \frac{u^{\prime}(q)}{g_{q}(q, Z)}+1-\sigma\right] \\
V_{b_{t}, t}\left(m_{t}, b_{t}, S_{t}\right)=\beta R_{t} \chi_{t} .
\end{gathered}
$$

where we used (8) and that $\partial q_{t} / \partial m_{t}=\beta \chi_{t} / g_{q}\left(q_{t}, Z_{t}\right)$.

\section{$2.3 \quad$ Firms}

In the CM, a representative firm hires labor in a competitive labor market and operates the linear production technology $Y_{t}=Z_{t} H_{t}$. Profit-maximization therefore implies the wage is $w_{t}=Z_{t}$ in equilibrium.

\subsection{Private-Sector Equilibrium}

Imposing equilibrium $\left(m_{t}=M_{t}, x_{t}=X_{t}\right.$, etc. $)$ and combining the firms' and households' opti-

mality conditions, we can define the equilibrium as follows. Given policy variables $\left\{\tau_{t}^{h}, R_{t}\right\}_{t=0}^{\infty}$, the technology realization $\left\{Z_{t}\right\}_{t=0}^{\infty}$, the government spending realization $\left\{G_{t}\right\}_{t=0}^{\infty}$, and initial condition $\left(M_{0}, B_{0}\right)$, equilibrium is a set of processes $\left\{q_{t}, B_{t}, M_{t}, X_{t}, H_{t}, P_{t}\right\}_{t=0}^{\infty}$ satisfying

$$
\begin{gathered}
U^{\prime}\left(X_{t}\right)=\frac{A}{\left(1-\tau_{t}^{h}\right) Z_{t}}, \\
\beta M_{t} E_{t}\left[\frac{U^{\prime}\left(X_{t+1}\right)}{P_{t+1}}\right]=g\left(q_{t}, Z_{t}\right), \\
\frac{U^{\prime}\left(X_{t}\right)}{P_{t}}=\beta\left[\sigma \frac{u^{\prime}\left(q_{t}\right)}{g_{q}\left(q_{t}, Z_{t}\right)}+1-\sigma\right] E_{t}\left[\frac{U^{\prime}\left(X_{t+1}\right)}{P_{t+1}}\right], \\
\frac{U^{\prime}\left(x_{t}\right)}{P_{t}}=\beta R_{t} E_{t}\left[\frac{U^{\prime}\left(x_{t+1}\right)}{P_{t+1}}\right] .
\end{gathered}
$$




$$
\begin{gathered}
X_{t}+G_{t}=Z_{t} H_{t} \\
M_{t}+B_{t}+P_{t} Z_{t} \tau_{t}^{h} H_{t}=P_{t} G_{t}+M_{t-1}+R_{t-1} B_{t-1} .
\end{gathered}
$$

where we used (2) and the definition of $\chi_{t}$ to get $\chi_{t}=E_{t}\left[U^{\prime}\left(x_{t+1}\right) / P_{t+1}\right]$. Combining (14) and (15) we get a no-arbitrage condition between money and bonds

$$
R_{t}=\sigma \frac{u^{\prime}\left(q_{t}\right)}{g_{q}\left(q_{t}, Z_{t}\right)}+1-\sigma
$$

For the Ramsey problem, it will be useful to combine (13) and (14) and rearrange for real money balances,

$$
\frac{M_{t}}{P_{t}}=\frac{g\left(q_{t}, Z_{t}\right)}{U^{\prime}\left(X_{t}\right)}\left[\sigma \frac{u^{\prime}\left(q_{t}\right)}{g_{q}\left(q_{t}, Z_{t}\right)}+1-\sigma\right]
$$

Furthermore, in any monetary equilibrium, $R_{t} \geq 1$ because otherwise households could earn unbounded profits by selling bonds and buying money. We represent this restriction in terms of allocations using (17) as

$$
\sigma\left(\frac{u^{\prime}\left(q_{t}\right)}{g_{q}\left(q_{t}, Z_{t}\right)}-1\right) \geq 0
$$

which we will call the zero-lower-bound (ZLB) constraint.

\section{Ramsey Problem}

As is common in the Ramsey literature, we adopt the primal approach and cast the Ramsey problem as that of a planner that chooses allocations subject to feasibility and the need to raise exogenous government revenue, making sure the resulting allocations are implementable as a monetary equilibrium. We prove the following in Appendix A.1:

Proposition 1. The allocations in a monetary equilibrium satisfy (16), (19), and the present-value implementability constraint (PVIC),

$$
E_{0} \sum_{t=0}^{\infty} \beta^{t}\left[U^{\prime}\left(X_{t}\right) X_{t}-A H_{t}+\sigma g\left(q_{t}, Z_{t}\right)\left(\frac{u^{\prime}\left(q_{t}\right)}{g_{q}\left(q_{t}, Z_{t}\right)}-1\right)\right]=U^{\prime}\left(X_{0}\right)\left[\frac{M_{-1}+R_{-1} B_{-1}}{P_{0}}\right] .
$$

In textbook Ramsey problems, implementability constraints typically take the form $E_{0} \sum_{t} \beta^{t} \sum_{i} U_{i}\left(x_{1 t}, \ldots, x_{N t}\right) x_{i t}=a_{0}$, where $\left\{x_{i t}\right\}_{i=1}^{N}$ is the set of $N$ goods the agent consumes at time $t .{ }^{6}$ At first glance, (20) does not seem to conform to this general form because the term related to the DM, $\sigma g\left(q_{t}, Z_{t}\right)\left(u^{\prime}\left(q_{t}\right) / g^{\prime}\left(q_{t}\right)-1\right)$ does not look like marginal utility of a good times the quantity of that good. However, this term does indeed have such an interpretation; we can show that the term in the PVIC is simply the product of money balances and its marginal utility.

\footnotetext{
${ }^{6}$ In the CCK model, for example, instantaneous utility is defined over cash goods, credit goods, and labor, $u\left(c_{1}, c_{2}, l\right)$, and the PVIC takes the form $\sum_{t=0}^{\infty} \beta^{t}\left[u_{1 t} c_{1 t}+u_{2 t} c_{2 t}+u_{l t} l_{t}\right]=A_{0}$, with $A_{0}$ a function of initial money and bonds. See Chari and Kehoe (1999, p. 1676-1686) for more discussion of optimal taxation problems in general.
} 
To see this, note that from the bargaining problem and $(8), S_{b}(q) \equiv u(q)-g(q, Z)$ is the surplus of the buyer and therefore $S_{b}^{\prime}(q) \equiv u^{\prime}(q)-g_{q}(q, Z)$ is the marginal surplus of the buyer. Moreover, money has no use in the DM unless the household is a buyer, which occurs with probability $\sigma$. Thus, the marginal utility of money can be expressed as $\sigma S_{b}^{\prime}(q) \partial q / \partial m$. From (8) we have $m=g(q, Z) / \beta \chi$ and $\partial q / \partial m=\beta \chi / g_{q}(q, Z)$. Combining these, we obtain the third term under the summation in the PVIC. With this interpreration, one may argue that our model looks like a MIU model, which would have a term $m U_{m}$ in the PVIC. In our context, though, the marginal utility of money is linked to the fundamentals of the economy - allocations and technology — and it is not an arbitrary function.

If $\sigma=0$, the DM shuts down and our PVIC collapses to the usual CCK PVIC in a real model. That is, the model collapses to a purely real model. This is due to the fact that when $\sigma=0$, the only source of money demand shuts down in our model and the only equilibrium of the model is the nonmonetary equilibrium.

We assume the Ramsey planner is able to commit at time zero to a policy for $t \geq 1$. We thus sidestep here the potentially interesting issue of time-inconsistency in this model. The Ramsey problem is thus to choose $\left\{X_{t}, H_{t}, q_{t}\right\}$ to maximize

$$
E_{0} \sum_{t=0}^{\infty} \beta^{t}\left\{U\left(X_{t}\right)-A H_{t}+\sigma\left[u\left(q_{t}\right)-c\left(q_{t}, Z_{t}\right)\right]\right\}
$$

subject to the CM resource constraint

$$
X_{t}+G_{t}=Z_{t} H_{t}
$$

the PVIC (20), and the ZLB constraint (19), taking as given $\left\{G_{t}, Z_{t}\right\}$. In the Ramsey objective functon (21), $\sigma\left[u\left(q_{t}\right)-c\left(q_{t}, Z_{t}\right)\right]$ arises because the planner aggregates over the measure $\sigma$ of buyers in the DM (each of whom experiences $u\left(q_{t}\right)$ ), the measure $\sigma$ of sellers in the DM (each of whom experiences $c\left(q_{t}, Z_{t}\right)$ ), and the measure $1-2 \sigma$ of households that do not trade in the DM. In Appendix A.2, we list the conditions that characterize the solution to this problem, along with the conditions that allow us to construct the policies and prices that support the Ramsey allocation. Thus, as we already noted, our approach is a straightforward application of Ramsey theory.

\section{Optimal Policy}

One of our central results is that for a range of values for $\theta$, the optimal nominal interest rate is positive. We can establish this analytically for the case $\theta=1$, which we do next. The case $\theta=1$ is an especially important one because Rocheteau and Wright (2005) show that for this case, bargaining yields the same outcomes as if there were competitive forces in the DM, making DM 
trades look less non-standard from the point of view of modern DGE theory. The $\theta=1$ case is as conceptually close as this class of models can get to a standard CCK-type environment. For $\theta<1$, analytical solutions are not as easy to obtain, and we resort to numerical solutions.

\subsection{Optimal Deviation from the Friedman Rule}

\subsubsection{Proof for $\theta=1$ (Buyer-Take-All Bargaining)}

The Friedman Rule is not optimal if $\theta=1$, as we now show:

Proposition 2. (Optimal Deviation from the Friedman Rule) If $\theta=1$, the optimal policy features a strictly positive net nominal interest rate in every period $t \geq 1$. Furthermore, if $u($. is CRRA (constant relative risk aversion) then the optimal nominal interest rate is constant over time.

Proof. Let $\xi$ be the multiplier on the PVIC (20) in the Ramsey problem, and consider the Ramsey problem with the ZLB constraint dropped. The first-order condition of this problem with respect to $q_{t}$ for $t \geq 1$ is given in Appendix A.2. With $\theta=1$, we have that $g(q, Z)=c(q, Z)=q / Z$, so this FOC simplifies considerably,

$$
u^{\prime}\left(q_{t}\right)-\frac{1}{Z_{t}}=-\left(\frac{\xi}{1+\xi}\right) q_{t} u^{\prime \prime}\left(q_{t}\right)
$$

Because $u$ is strictly concave, the multiplier $\xi>0$ under any interesting Ramsey allocation, and of course $q_{t}>0 \forall t$ in a monetary equilibrium, the right hand side of the first order condition above is strictly positive. This implies $u^{\prime}\left(q_{t}\right)>1 / Z_{t}$, which in turn implies

$$
\sigma \frac{u^{\prime}\left(q_{t}\right)}{g_{q}\left(q_{t}, Z_{t}\right)}+1-\sigma>1,
$$

imposing $g_{q}(q, Z)=c_{q}(q, Z)=1 / Z$ because $\theta=1$. But this implies, by the equilibrium condition (17), that $R_{t}>1$, so we have established that the Friedman Rule is not optimal.

Next, suppose $u(q)=q^{(1-\eta)} /(1-\eta)$. Looking at (17), we see that for $R_{t}$ to be constant over time, $u^{\prime}\left(q_{t}\right) / g_{q}\left(q_{t}, Z_{t}\right)$ has to be constant. With $\theta=1$, this requires that $Z_{t} u^{\prime}\left(q_{t}\right)$ is constant. The CRRA utility function has the property $q_{t} u^{\prime \prime}\left(q_{t}\right)=-\eta u^{\prime}\left(q_{t}\right)$. Imposing this in (22) and collecting the $Z_{t} u^{\prime}\left(q_{t}\right)$ terms, we have

$$
Z_{t} u^{\prime}\left(q_{t}\right)=\left[1-\eta\left(\frac{\xi}{1+\xi}\right)\right]^{-1},
$$

which shows that $Z_{t} u^{\prime}\left(q_{t}\right)$ is constant.

Deviations from the Friedman Rule have been obtained in other Ramsey models, as well. For example, Schmitt-Grohe and Uribe (2004a) show that a positive nominal interest can tax producers' monopoly profits, and Chugh (2006) shows that it can tax monopolistic labor suppliers' rents. We 
know from Ramsey theory that taxing rents is optimal because it is non-distorting. However, the deviations from the Friedman Rule in Schmitt-Grohe and Uribe (2004a) and Chugh (2006) are instances of the Ramsey planner using a positive nominal interest rate to indirectly tax some rent - in neither case is activity requiring money the ultimate object the Ramsey planner seeks to tax. As we discuss in Section 5, the deviation from the Friedman Rule that arises in our model is due to a concern for directly taxing activity requiring cash; we also offer a rent-seizing interpretation that allows us to conceptually connect our results to CCK.

Regardless of the interpretation, though, a consequence of a positive nominal interest rate is that DM activity (i.e., $q_{t}$ ) is below its Pareto-optimal level. From the perspective of the results in LW and much of the ensuing related work, which invariably find that $q=q^{*}$ is optimal, it is surprising to entertain the idea that $q<q^{*}$ is optimal in any sense. However, as we mentioned at the outset, a Ramsey problem — which is one about financing of government activities — is inherently one about creating "optimal inefficiencies." A standard result in public finance is that such inefficiencies ought to be spread across all final goods. Because $q$ is of course a final good, we have $q<q^{*}$.

One may wonder, then, if there is another instrument that, if the Ramsey planner had it available and were to use it, would reinstate the optimality of the Friedman Rule. A natural candidate is a sales tax in the DM. We show in Section 5 that allowing for a DM sales tax in a straightforward way leads to exactly the same Ramsey allocation problem that we have been studying. With the presence of an additional policy instrument, an indeterminacy arises between its use and the use of the inflation tax. A non-generic policy that decentralizes the same exact allocation that we have already obtained involves setting the Friedman Rule along with some appropriate DM sales tax rate. This does not overturn our main result that the Friedman Rule is typically - generically - not optimal. We also point out that if one allowed for, say, a proportional subsidy to cash good consumption in the CCK model, then a deviation from the Friedman Rule combined with an appropriate subsidy would generically be the optimal policy there. Again, this possibility is admitted due to an indeterminacy across instruments.

Leaving aside other instruments, then, left to still consider is the quantitative degree of the departure from the Friedman Rule. The rent-seizing argument we alluded to above and discuss further in Section 5 would suggest that the optimal inflation rate should be one that confiscates the entire rent, but this would imply $q=0$. Thus, the optimal inflation rate must balance the motive to seize the money rent versus pushing $q$ too low. Our numerical results, presented next for both $\theta=1$ and the more general case $\theta<1$, confirm this intuition. 


\subsubsection{Numerical Results}

Obtaining analytic solutions for $\theta<1$ is not as easy, so we study the optimal steady-state policy for this case numerically, using the full set of non-linear Ramsey conditions. Before presenting numerical results, we briefly describe the parameterization of the model. To the extent possible, we use the parameters and functional forms that LW provide, whose model is calibrated to match some long-run features of the US economy.

The DM utility function is

$$
u(q)=\frac{(q+b)^{1-\eta}-b^{1-\eta}}{1-\eta},
$$

with $b=0.0001$, which is a parameter that forces $u(0)=0$, which can occur in the DM if a household does not meet another agent with whom to trade. In the CM, instantaneous utility is $B \ln (X)-H$.

We consider two cases: buyer-take-all in the bargaining problem $(\theta=1)$, which is equivalent to price-taking, and $\theta<1$. For the former case we use $(\eta, B, \sigma)=(0.27,2.13,0.31)$ and for the latter case we use $(\eta, B, \sigma, \theta)=(0.39,1.78,0.5,0.34)$.

The exogenous government spending and TFP processes each evolve as an AR(1) in logs,

$$
\begin{gathered}
\ln G_{t+1}=\left(1-\rho_{G}\right) \ln \bar{G}+\rho_{G} \ln G_{t}+\epsilon_{t+1}^{G}, \\
\ln Z_{t+1}=\rho_{Z} \ln Z_{t}+\epsilon_{t+1}^{Z},
\end{gathered}
$$

with $\epsilon^{G} \sim N\left(0, \sigma_{\epsilon^{G}}^{2}\right)$ and $\epsilon^{Z} \sim N\left(0, \sigma_{\epsilon^{Z}}^{2}\right)$. We calibrate $\bar{G}=0.4$, so that government purchases constitute about 18 percent of total GDP in steady-state. ${ }^{7}$ In line with Schmitt-Grohe and Uribe (2004b) and the RBC literature, we set the parameters of the stochastic processes $\sigma_{\epsilon^{G}}=0.033$, $\sigma_{\epsilon^{Z}}=0.007, \rho_{G}=0.89$, and $\rho_{Z}=0.81$. With these volatility parameters, our model has a standard deviation of government purchases of about 7 percent of the mean level of government spending, and the volatility of total output is about 1.8 percent, both in line with data. The persistence parameters of the exogenous processes are for an annual calibration, thus we set the annual subjective discount factor $\beta=0.962$, which delivers an annual real interest rate of about 4 percent. Finally, we choose the level of steady-state government debt, an object not pinned down by the model, so that it is 45 percent of steady-state output, consistent with the parameterizations of CCK and Schmitt-Grohe and Uribe (2004b).

The solid line in Figure 1 shows the steady-state Ramsey policy and key allocation variables as functions of $\theta$. At $\theta=1$, the optimal nominal interest rate is about 2 percent at an annual rate; the associated optimal inflation rate is thus -1.6 percent, higher than the Friedman rate of deflation, which would be -3.4 percent in our model.

\footnotetext{
${ }^{7}$ Real GDP takes into account both $\mathrm{CM}$ and DM output: $\sigma M / P+Z H$.
} 
As $\theta$ falls below unity, the optimal nominal interest rate falls. This is due to a combination of the holdup problem associated with holding money when $\theta<1$ discussed by LW and the nonmonotonicity of the Nash bargaining solution discussed by Aruoba, Rocheteau and Waller (2007). The former effect predicts that if $\theta<1$, the buyer does not obtain the full benefit from a match, which reduces his incentives to hold money (i.e. he is held-up by the seller), causing the equilibrium $q$ to fall. The latter affect arises from the fact that when $\theta<1$, the level of real money balances that maximize the buyer's surplus is lower than the socially optimal level. In Section 5.1.5 we disentangle the two effects by considering a bargaining solution that satisfies individual monotonicity, and we show that for any buyer's surplus share, the Friedman Rule is not optimal. Taking into account both of these (dis)incentives, the Ramsey planner reduces the inflation tax as $\theta$ falls below unity - this balances the planner's desire to tax the buyer's surplus against the desire to reduce the effects of the holdup and nonmonotonicity problems. Because seignorage revenue (not shown) falls along with the nominal interest rate, the government's revenue shortfall must be made up with the labor tax, causing the labor tax rate to rise, as the top right panel of Figure 1 shows.

The associated responses of the allocation variables $q$ and $X$ are easy to understand as well. We again emphasize that $q$ is below its Pareto-optimal level, which, given all the particulars of the LW environment, is $q^{*}=1$ at the steady state. Finally, and as is intuitive, as the labor income tax rate rises with the fall in $\theta$, hours worked and hence consumption in the CM decline.

If $\theta$ falls far enough the ZLB constraint binds, making the Friedman Rule the optimal policy. For our calibration, the ZLB constraint binds if $\theta \in(0,0.62)$, as can be seen by the fact that the net nominal interest rate is zero over that interval. The kink when the ZLB constraint binds leads to kinks in the labor tax rate and allocations as well.

The dotted line in Figure 1 shows the allocations and implied $R$ and $\tau^{h}$ that emerge from the Ramsey problem with the ZLB constraint (19) dropped. The results for $\theta \in(0.62,1)$ are of course identical because in that region the ZLB constraint did not bind anyway. With the ZLB constraint dropped and $\theta \in(0,0.62)$, we see that the Ramsey planner would like to implement, if it were consistent with monetary equilibrium, a negative net nominal interest rate, apparently to boost $q$. Of course, deflation faster than the Friedman Rule is inconsistent with a monetary steady-state equilibrium. Hence, the Friedman Rule becomes the constrained optimal policy.

\subsection{Optimal Inflation Stability}

We now turn to the dynamics of the Ramsey policy, which reveals our second central result: optimal inflation is very stable in the face of business-cycle magnitude shocks. To investigate the dynamic behavior of our model, we solve for the dynamic Ramsey equilibrium and simulate the model. We 
conduct 1000 simulations of 500 periods each and discard the first 100 periods. As in Khan, King, and Wolman (2003) and others, we assume that the initial state of the economy is the asymptotic Ramsey steady state. For each simulation, we then compute first and second moments and report the averages of these moments over the 1000 simulations. We offer some details and observations regarding solving for the dynamics of our model and then present results.

As we explain in Appendix A.2, given $\left\{Z_{t}, G_{t}\right\}$, the first-order conditions of the Ramsey problem and the feasibility condition for the $\mathrm{CM}$ characterize the allocations $\left\{q_{t}, X_{t}, H_{t}\right\}$ and the multiplier on the ZLB constraint, $\left\{\iota_{t}\right\}$. Then we can use the equilibrium conditions to back out $\left\{\tau_{t}^{h}, R_{t}, \pi_{t}\right\}$. To reduce computational time, we approximate both the functions $q\left(Z_{t}, G_{t}\right)$ and $X\left(Z_{t}, G_{t}\right)$, as well as $\pi\left(Z_{t}, G_{t}\right)$. Our strategy is to construct global nonlinear approximations of these functions because of the presence of the potentially occasionally-binding ZLB constraint. ${ }^{8}$ Of interest to many practitioners, however, should be our (unreported) findings that, for the versions of the model in which we know for sure the ZLB constraint is always slack, first-order and second-order local approximations yielded results virtually identical to our global approximation. ${ }^{9}$ To construct the approximations, we use as the functional equations the first-order conditions of the Ramsey problem with respect to $q_{t}$ and $X_{t}$ and the equilibrium condition (14). We use the remaining equations to solve for the other variables of interest.

Before turning to simulations, we make a few observations by inspecting the first-order conditions of the Ramsey problem. First, government spending affects only CM hours because none of the first-order conditions for $q_{t}, X_{t}$, and $\iota_{t}$ (the multiplier on the ZLB constraint) involve $G_{t}$. Once $X_{t}$ is determined, $H_{t}$ adjusts according to the shocks to $G_{t}$. This result follows from the quasi-linearity of preferences in the CM. Because households essentially have risk-neutral preferences over hours, fluctuations in $G_{t}$ are fully reflected in $H_{t} .{ }^{10}$ Second, and related, the dynamics of $q_{t}$ and $X_{t}$ follow the dynamics of the technology shock as the latter is the only driving force for the former. Third, for the particular utility function we choose in the CM - in fact for any CRRA utility function — the labor income tax rate is constant over time. ${ }^{11}$ This can be viewed as the extreme case of the usual consumption-smoothing motive as spelled out in, say, Barro (1979).

\footnotetext{
${ }^{8}$ We approximate these functions using linear combinations of Chebyshev polynomials, following Judd (1992). Results from Aruoba, Fernandez-Villaverde and Rubio-Ramirez (2006) and Aruoba, Waller, and Wright (2006) indicate that this approximation method is very accurate. While our algorithm allows the ZLB to be an occasionally binding constraint, which means the multiplier $\iota\left(Z_{t}, G_{t}\right)$ may have one or more kinks in it, our quantitative results indicate that for the parameterizations we use the ZLB either always binds or never binds.

${ }^{9}$ Of course, this statement only holds for sufficiently-small driving shocks; the business-cycle magnitude shocks that we assume are apparently small enough.

${ }^{10}$ To make this point more clear, if we shut down the technology shock, then all variables except for $H_{t}$ will remain at their steady state values, and $H_{t}$ will fluctuate in line with $G_{t}$.

${ }^{11}$ This follows from the fact that $Z_{t} U^{\prime}\left(X_{t}\right)$ is constant. This can be seen easily from the first-order condition of the Ramsey planner for $X_{t}$.
} 
Table 1 presents simulation-based moments for the key allocation and policy variables for $\theta=1$ (which, again, is equivalent to price-taking) and for $\theta<1$. Let us first discuss the results for $\theta=1$. The first three rows show the dynamics of realized inflation, the labor income tax rate, and the net nominal interest rate under the Ramsey policy. We hone in first on the result that the optimal inflation rate is quite smooth over time, with a standard deviation of about only about 24 basis points (at an annual rate) around a mean deflation rate of 2 percent. The very stable inflation rate is in sharp contrast to the extremely volatile optimal inflation rate first found by CCK in a flexible-price Ramsey model and recently verified in, among others, the flexible-price versions of Schmitt-Grohe and Uribe (2004a, 2004b), Siu (2004), and Chugh (2006, 2007). ${ }^{12}$

In these baseline Ramsey monetary models, inflation does not distort the relative prices of goods. It is easiest to see this in a cash-credit economy: the nominal price of both cash and credit goods is $P$, and the relative price depends only on the nominal interest rate, reflecting the opportunity cost of the money used to purchase the cash good. In other words, given a nominal interest rate, dynamic fluctuations in the price level do not alter the relative price between cash and credit goods and therefore do not affect equilibrium allocations. In these baseline models, then, the driving force behind price-level dynamics is just the (desirable) ability of price-level fluctuations to tailor the real returns on nominal government debt, thus avoiding the need to change other distortionary taxes in the face of shocks to the government budget. Quantitatively, assuming business-cycle magnitude shocks, realized inflation turns out to be very volatile. ${ }^{13}$

With money essential, this result is overturned because inflation affects the relative price of DM and CM goods. We discuss the mechanism behind the optimality of inflation stability more fully in Section 5, but the basic idea is that inflation affects the relative price between DM and CM goods in a way that simply does not exist in a baseline Ramsey model. In a baseline Ramsey model, "cash goods" and "credit goods" are assumed to have a unit marginal rate of transformation, meaning their nominal prices (excluding the relative price induced by a positive nominal interest rate) are by construction identical. With a unit relative price by construction, variations in inflation affect both nominal prices equally. In contrast, in our model "cash goods" $(q)$ and "credit goods" $(X)$ do

\footnotetext{
${ }^{12}$ From their simulation experiments, CCK report a mean inflation rate of -0.44 percent with a standard deviation of 19.93; Schmitt-Grohe and Uribe (2004a) report a mean inflation rate of -3.39 percent with a standard deviation of 7.47 percent; Siu (2004) reports a mean inflation rate of -2.59 percent with a standard deviation of 5.08 percent; and Chugh (2006) reports a mean inflation rate of -4.01 percent with a standard deviation of 6.96 percent. Each of these models is calibrated in a slightly different way from the others, but the general result that comes through is clear: with flexible-prices, the Ramsey inflation rate is quite volatile.

${ }^{13}$ We also point out that with the assumption of full commitment on the part of the Ramsey planner, the use of state-contingent inflation is not a manifestation of time-inconsistent policy. The "surprise" in surprise inflation is due solely to the unpredictable components of government spending and technology, and not due to a retreat on past promises.
} 
not have a fixed unit relative price. Hence, variations in inflation have the potential to distort their relative price. Usual tax-smoothing reasons then suggest that it is optimal to have low volatility in inflation because otherwise the margin between DM and CM goods would be disrupted. Our quantitative results show that this channel is quantitatively powerful.

Other Ramsey models make the prediction that inflation stability is optimal, most notably Schmitt-Grohe and Uribe (2004b), Siu (2004) and Chugh (2006). The basic mechanism behind their inflation stability results is also a relative-price distortion caused by inflation; however, these models all rely on nominal rigidities to generate the relative-price effect. We emphasize that in our model, prices are fully flexible and yet inflation causes relative price distortions. The real frictions underlying monetary exchange are behind our result.

An important feature of inflation dynamics is that it displays high persistence. In the benchmark CCK model, which assumed fixed capital, inflation persistence is virtually zero no matter how persistent are the driving shocks. Chugh (2007) shows that allowing for capital accumulation or habit formation in preferences generates optimal inflation persistence, but clearly here we have that result with neither of these features. The high persistence of Ramsey-optimal inflation is also helpful in understanding the low volatility of inflation, as we discuss in Section 5.

Finally, consider the results for $\theta<1$, reported in the second panel of Table 1 . The means of the variables of interest are of course in line with the steady state results. Compared to the price-taking case $(\theta=1)$, the average labor income tax rate is higher and average consumption (both CM and DM) and GDP are lower. The Friedman rule is optimal with an average deflation equal to the rate of time preference. In our simulations, which are driven by business-cycle-magnitude shocks, we find that the optimal nominal interest rate is once again constant over time. ${ }^{14}$ We also find that $q_{t}$ is less volatile if $\theta<1$, which in turn causes GDP to be less volatile and the correlations of other variables with GDP to be lower than what we find when $\theta=1$. In short, we find that except for the expected changes in the means, the dynamic behavior of the Ramsey problem with $\theta<1$ is qualitatively identical to the case with $\theta=1$.

\section{Discussion}

Here, we expand on the analysis and intuition behind our main results. We divide our discussion into two parts, first further analyzing our long-run results and then further analyzing our dynamic results.

\footnotetext{
${ }^{14}$ However, this result is not robust to large shocks. In simulations not reported here, we considered very large negative technology shocks (a standard deviation of more than 60 percent of the average). When hit by these large shocks, the Ramsey solution includes small deviations from the Friedman rule.
} 


\subsection{Optimal Deviation from the Friedman Rule}

As we mentioned above, one may be concerned about the sensitivity of our results to the inclusion of a richer set of policy instruments. Such a concern can be justified by, for example, the results of Correia, Nicolini, and Teles (2002), who show in a sticky-price Ramsey model that a rich set of instruments can allow for the Friedman Rule to re-emerge, albeit as part of a non-generic policy. Such a conclusion carries over to our model as well - however, as we show, allowing for a wide range of natural instruments that could be used in the DM or the CM does not alter the basic prescription that DM activity should be taxed. Throughout what follows, we focus on the case $\theta=1$ because that is the case for which provide analytical results.

\subsubsection{Alternative Instruments in the DM}

Consider a proportional sales tax on DM transactions. We introduce a DM sales tax in the following way: after a buyer turns over to a seller $\tilde{P}_{t} q_{t}$ units of money in a DM trade $\left(\tilde{P}_{t}\right.$ denotes the nominal price of DM goods), the seller must remit $\tau_{t}^{d} \tilde{P}_{t} q_{t}$ to the government in the next CM, which, given our timing assumptions, occurs in period $t+1 .{ }^{15}$ Equivalently, we can suppose that the government receives the revenue in the DM but waits until the next CM to spend it. Because asset markets are not open in the DM, the government cannot invest this extra revenue in an interest-bearing asset (nor can sellers, for that matter).

The solution to the DM bargaining problem in expression (8) modifies to

$$
\beta Z_{t} \chi_{t}\left(1-\tau_{t}^{d}\right) m_{t}=q_{t}
$$

In terms of other private-sector equilibrium conditions relevant for the Ramsey problem, conditions (17) and (18) modify to, respectively,

$$
R_{t}=\sigma\left(1-\tau_{t}^{d}\right) Z_{t} u^{\prime}\left(q_{t}\right)+1-\sigma
$$

and

$$
\frac{\left(1-\tau_{t}^{d}\right) M_{t}}{P_{t}}=\frac{q_{t}\left[\sigma\left(1-\tau_{t}^{d}\right) Z_{t} u^{\prime}\left(q_{t}\right)+1-\sigma\right]}{Z_{t} U^{\prime}\left(X_{t}\right)} .
$$

To construct the PVIC, we must begin by summing the CM budget constraints of all households (a measure $\sigma$ of whom were buyers in period $t-1$ and thus enter period $t$ with no money; a measure $\sigma$ of whom were sellers and thus enter period $t$ with $M_{t-1}+\left(1-\tau_{t-1}^{d}\right) M_{t-1}$; and a measure $1-2 \sigma$ of whom did not trade and thus have $M_{t-1}$ ), which yields

$$
P_{t} X_{t}+M_{t}+B_{t}=P_{t} w_{t}\left(1-\tau_{t}^{h}\right) H_{t}+\left(1-\sigma \tau_{t-1}^{d}\right) M_{t-1}+R_{t-1} B_{t-1}
$$

\footnotetext{
${ }^{15}$ Thus, we assume that it is the sellers that pass along the sales tax receipts to the government; assuming that it is buyers that remit taxes would formally lead to the same conclusion.
} 
Proceeding to construct the PVIC exactly as we show in Appendix A.1 (and now using the modified equilibrium conditions (23) and (24)), one can show that the PVIC is the same as in (20), except for the fact that $\tau_{-1}^{d}$ appears as part of the constant term on the right-hand-side. Because optimization begins in period zero, we treat $\tau_{-1}^{d}$ as fixed and, in particular, equal to zero.

Thus, the Ramsey allocation problem is identical to that without the DM sales tax. What can now differ, of course, is the precise way in which the Ramsey allocation is decentralized. Given the Ramsey allocation, an indeterminacy arises between the nominal interest rate and the DM sales tax, as condition (23) shows. Generically, the Friedman Rule still fails to emerge. One particular policy, however, is to set the Friedman Rule along with whatever DM sales tax rate is required. Thus, we can recover the optimality of the Friedman Rule; but this recovery is trivial because we do not recover zero taxation of activities requiring cash, which means we do not recover the Pareto-optimal level of $q$.

Another type of "direct" tax on DM activity one could entertain is to tax the surplus accruing to buyers. If we were to introduce a $\left(1-\tau^{\text {surplus }}\right)$ in front of the first term on the right-hand-side of (6), this "surplus tax" would pre-multiply the third term under the summation in the PVIC (20). Ramsey optimization with respect to this instrument would lead to $\tau^{\text {surplus }}=1$, which would then recover the Friedman Rule. However, surpluses that are bargained over in the DM are defined in terms of utils. We do not see any sensible interpretation under which it makes sense for utils to be taxed, and, moreover, for the government to be able to "convert" utils into real resources that would help it finance its budget. Thus, "surplus taxation" schemes are not viable given the primitives of our environment.

\subsubsection{Alternative Instruments in the CM}

We could also imagine adding other instruments in the CM. The standard intuition is that positive nominal interest rates tax money holdings. Thus, imagine that the government could directly tax households' choice of money holdings. While this is of course a non-standard tax instrument, we use it to illustrate that a deviation from the Friedman Rule in our model does precisely what standard intuition suggests: it taxes money balances.

To implement a tax on money balances, replace the $m_{t}$ on the left hand side of the household CM budget constraint (1) with $\left(1+\tau_{t}^{m}\right) m_{t}$, where $\tau_{t}^{m}$ is the tax rate on money holdings. Tracing this tax through the derivation of the equilibrium conditions, condition (17) modifies to $\left(1+\tau_{t}^{m}\right) R_{t}=$

$\sigma \frac{u^{\prime}\left(q_{t}\right)}{g_{q}\left(q_{t}, Z_{t}\right)}+1-\sigma$, while in condition (18) the term $\left(1+\tau_{t}^{m}\right)$ appears in the denominator of the lefthand-side. Using the same manipulations as in Appendix A.1, it is easy to show that the Ramsey PVIC is identically (20). Thus, the Ramsey allocation is identical. Clearly, given the Ramsey allocation, an infinite number of combinations $\left(R, \tau^{m}\right)$ decentralize it, one of which involves the 
Friedman Rule. However, again in accord with Ramsey theory and as we argued above for the case of a DM sales tax, this is an uninteresting way of reinstating the Friedman Rule because we have handed the Ramsey government a redundant instrument. The more interesting point is that some sort of taxation of money balances is required, and, as we have already argued, inflation is a natural way of achieving this.

One could also insert a proportional tax on CM consumption. Denoting such a tax by $\tau_{t}^{x}$, clearly the only equilibrium condition where this tax will show up is in the CM consumptionleisure optimality condition (12), which has the effect of rendering indeterminate the split of the consumption-leisure wedge between the CM consumption tax and the CM labor tax. This indeterminacy is standard and does nothing to alter our conclusions regarding taxation of money holdings.

\subsubsection{Comparison of Results with CCK}

Our conclusion that the Friedman Rule is not optimal of course differs from that of CCK. At a technical level, it can be reconciled with their result by considering basic principles of public finance. In CCK, optimality of the Friedman Rule depends on a certain class of utility functions. In particular, CCK require cash goods and credit goods to enter the utility function homothetically and separably from leisure. Similarly, in Chari and Kehoe's (1999) MIU model, money and consumption must enter utility homothetically and separably from leisure in order for the Friedman Rule to be optimal. These results are essentially an application of the uniform taxation result of Atkinson and Stiglitz (1980), requiring cash-good consumption and credit-good consumption (or money and consumption) to be taxed uniformly; a deviation from the Friedman Rule would mean that cash goods are taxed more heavily than credit goods, hence cannot be optimal.

With $\theta=1$, the instantaneous social utility function (the one that the Ramsey planner maximizes) in our model takes the form $\mathcal{U}(q, X, e, h)=\sigma[u(q)-e]+U(X)-A H$ (e denotes the effort of sellers in the DM). If we interpret $q$ as the cash good and $X$ as the credit good, $q$ and $X$ must enter $\mathcal{U}$ homothetically to satisfy the CCK requirement. Our Proposition 2 admits this case. For example, we can set $u()=.U($.$) and Proposition 2$ of course still holds. However, realize that, given the structure of the LW model, $e=q / Z$. The reduced-form social utility function thus has the form $\tilde{\mathcal{U}}(q, X, h)=\sigma[u(q)-q / Z]+U(X)-A H$, and $q$ and $X$ will in general not enter $\tilde{\mathcal{U}}(q, X, h)$ homothetically. In other words, even though we have homothetic preferences in terms of the primitives, the reduced-form representation, which is the one relevant for the Ramsey planner, does not feature homothetic preferences. Our results thus reconcile in a technical sense with those of CCK.

Given the lack of homotheticity of the social welfare function, there is no presumption that the CCK result carries over to our environment. If we had simply started with the reduced-form 
social welfare function, one may have easily guessed the CCK result would not hold; doing so, of course, would have begged the question of how such social preferences arise. In our setting, the social welfare function arises from the primitives of the LW environment. As we show below, the suboptimality of the Friedman Rule also holds in some natural and existing extensions of the LW environment. Before turning to those extensions, however, we offer a more conceptual reconciliation of our results with those of CCK and standard Ramsey theory.

\subsubsection{Rents Associated with DM Activity}

Given the fundamental need to tax activities requiring money, we think one useful way of considering the deviation from the Friedman Rule is that it stems from the presence of a rent associated with DM activity. To make ideas as clear as possible, consider again the case $\theta=1$. Recall that the entire surplus of a DM trade is obtained by the buyer with $\theta=1$. We noted above that the instantaneous social welfare function in our model takes the form $\sigma[u(q)-e]+U(X)-A H$. Define $W(q, X) \equiv \sigma[u(q)-e]+U(X)$. The $e$ term in $W($.$) can be thought of as a scarce, or fixed, factor$ in the social utility function. More precisely, from the perspective of a buyer, $e$ is inelastic with respect to any of his actions because $e$ represents the (utility) cost to the seller. The social welfare function aggregates preferences over both households that turn out to be buyers and those that turn out to be sellers. With $\theta=1$, the full surplus of DM trades accrues to buyers, a feature of equilibrium that the Ramsey planner of course understands; hence, maximization of the social welfare function can be interpreted as maximization of simply buyers' utility. From the Ramsey point of view, the $e$ term can be therefore viewed as a fixed factor in preferences.

With this way of thinking about the optimal policy problem, our results and interpretation fit squarely into something pointed out by Chari and Kehoe (1999, p. 1734-1735): if preferences exhibit decreasing returns in cash goods (our $q$ ) and credit goods (our $X$ ) because of a scarce factor that affects preferences of cash goods, then the Friedman Rule is not optimal. ${ }^{16}$ Their literal interpretation was that the fixed factor was something supplied inelastically by the representative household. In our model, the latter part of this intuition is modified to something inelastically supplied by some household because there is no representative household in the DM - rather, expost, there are three types of households. The Ramsey planner, though, aggregates over all types, so the "reduced-form" preferences feature this type of scarce factor in preferences. Note that this not an artifact of some strange aggregation scheme: the Ramsey planner considers the ex-ante utility of all agents, and households ex-ante do not know their DM type.

\footnotetext{
${ }^{16}$ As another exercise, we solved numerically for the optimal long-run policy in a basic CCK model assuming that preferences over cash goods and credit goods took the ad-hoc form $v\left(c_{1}, c_{2}\right)=\sigma\left[u\left(c_{1}\right)-c_{1} / Z\right]+U\left(c_{2}\right)$. Even with $u()=.U($.$) , we found, not surprisingly, that the optimal nominal interest rate was positive.$
} 
Fixed factors are the source of rents. In our model, the scarce factor and hence the source of rents is fundamentally related to DM activity. Hence arises our model's prescription to tax DM activity, be it through inflation, which we think is quite natural, through the DM sales taxes we described above, through the less natural direct taxation of money balances we also described above, or any combination of these. Of course, in our model, the fixed factor is not something we arbitrarily introduce into preferences to obtain a deviation from the Friedman Rule - rather, it arises from the primitives of the environment.

\subsubsection{Alternative Model Specifications}

We consider two alternative specifications for which we can prove variants of our Proposition 2 above. First, we drop the within-period separability assumption for utility and suppose the household's utility function is given by $U(X, q)$. We are able to prove that if $U_{q x}(X, q)<0$, i.e. if $q$ and $X$ are Edgeworth substitutes, then a deviation from the Friedman rule continues to be optimal.

Second, we consider a different pricing scheme in the DM. We assume that the buyer and the seller split the surplus with the share $\theta$ received by the buyer. As Aruoba, Rocheteau and Waller (2007) show, the only change in the equilibrium is that the function $g(q, Z)$ in $(9)$ is replaced by

$$
g(q, Z)=(1-\theta) u(q)+\theta c(q, Z)
$$

with all equilibrium conditions and Ramsey optimality conditions unchanged. We are able to prove that for any $\theta>0$ the Friedman rule is not optimal. This substantiates our intuition in Section 4.1.2 that the non-monotonicity of the Nash bargaining solution is the reason underlying the Friedman rule becoming the constrained optimal policy as $\theta$ falls.

\subsection{Optimal Inflation Stability}

Here, we offer some other perspectives on our inflation stability result.

\subsubsection{Relative Price Distortions}

The fact that inflation exhibits quite low volatility in the face of shocks seems to stem from stabilization of the relative price $\tilde{P}_{t} / P_{t}$ of $\mathrm{DM}$ and CM goods (where, as above, $\tilde{P}_{t}$ denotes the nominal price of a DM good). Using equilibrium conditions, we can show that this relative price, in an arbitrary private-sector equilibrium, can be expressed as

$$
\frac{\tilde{P}_{t}}{P_{t}}=\frac{R_{t}}{Z_{t} U^{\prime}\left(X_{t}\right)} .
$$


We showed in Proposition 2 that for CRRA preferences the Ramsey equilibrium features $R_{t}=$ $R \forall t$. Furthermore, in the Ramsey equilibrium, $Z_{t} U^{\prime}\left(X_{t}\right)$ is also constant over time for CRRA preferences (see footnote 13). Thus, the relative price $\tilde{P}_{t} / P_{t}$ is constant in the Ramsey equilibrium.

The issue thus becomes how or why (near-complete) stabilization of inflation is associated with or required for (complete) stabilization of this relative price. Another way to express the equilibrium value of this relative price is, using (14) and (18),

$$
\frac{\tilde{P}_{t}}{P_{t}}=\frac{g\left(q_{t}, Z_{t}\right)}{\beta E_{t}\left[U^{\prime}\left(X_{t+1}\right) / \pi_{t+1}\right]} .
$$

Due to covariance with $U^{\prime}\left(X_{t+1}\right)$, the term in the denominator on the right-hand-side is of course not simply expected future inflation, but our intuition for how movements in $\pi_{t}$ affect $\tilde{P}_{t} / P_{t}$ stems from how movements in $\pi_{t}$ transmit into movements in $E_{t} \pi_{t+1}$.

We can track the dynamic behavior of $E_{t} \pi_{t+1}$ in our model by forecasting, using our approximated decision rules, the expected one-period-ahead Ramsey inflation rate along our simulations. Across all our simulations, the correlation between $\pi_{t}$ and $E_{t} \pi_{t+1}$ is extremely high, at 0.99 . More importantly, the volatilities of $\pi_{t}$ and $E_{t} \pi_{t+1}$ are virtually identical. These two observations lead to the conclusion that the dynamics of $\pi_{t}$ and $E_{t} \pi_{t+1}$ are virtually identical under the Ramsey plan in our model, which we can also verify simply by inspecting time-series plots of these variables from our simulations.

This is the opposite of what occurs in a basic CCK model. In a basic CCK model, $\pi_{t}$ is very volatile, yet $E_{t} \pi_{t+1}$ is very stable, always remaining very close to its unconditional (i.e., deterministic steady-state) mean. The fact that the dynamics of $\pi_{t}$ and $E_{t} \pi_{t+1}$ are extremely similar in our model is consistent with the finding we noted above that Ramsey-optimal inflation is highly persistent in our framework. The fact that the dynamics of $\pi_{t}$ and $E_{t} \pi_{t+1}$ are extremely dissimilar in a basic CCK model is consistent with the CCK result that Ramsey-optimal inflation displays virtually zero correlation

The upshot of this analysis is that unanticipated inflation leaves an imprint on expected future (one-period-ahead) inflation in our model, and low volatility in the latter is required to maintain a stable relative price across the DM and the CM. This kind of policy transmission channel simply does not exist in a CCK model because contemporaneous inflation is so little correlated with conditional expectations of future inflation and hence does not distort activity.

\subsubsection{Dissipation of Exogenous Volatility}

Our settings for the standard deviations of the shocks to TFP and government purchases are in line with CCK, Schmitt-Grohe and Uribe (2004b), Siu (2004), and Chugh (2006). In all these models, relatively low volatility of inflation goes hand-in-hand with relatively high volatility of labor income 
tax rates. Given that our model predicts that both inflation and labor income tax rates exhibit very low volatility, it is of interest to know where the volatility of the exogenous driving forces "goes" in our model.

One mechanism through which volatility can be dissipated is through quasi-linearity of preferences. Because households are essentially risk-neutral with respect to their CM level of hours worked, some volatility of aggregate $H_{t}$ is tolerable from the Ramsey point of view. In the first row of Table 2, we report the volatility of key Ramsey policy and allocation variables in a version of the CCK model featuring linear-in-labor preferences. ${ }^{17}$ The volatility of inflation, at 3.24 percent, is a bit lower than the CCK benchmark (see footnote 14 above), and the volatility of $H_{t}$, at 1.13 percent, is a bit higher than the CCK benchmark. Thus, quasi-linearity of preferences and the attendant rise in volatility of equilibrium labor explains part of the dissipation of volatility. But it clearly does not explain all of it, given that our model's inflation volatility is still an order of magnitude smaller.

To further understand the result, we also tabulate the volatilities of Ramsey-equilibrium real money balances and government debt outstanding at the end of period $t-1$. By the latter, we mean the nominal debt issued by the government in period $t-1$, valued at the price level of period $t-1$; that is, we define $b_{t-1} \equiv B_{t-1} / P_{t-1}$. Important to realize is that $b_{t-1}$ is distinct from the real debt repayments made by the government in period $t$ - in terms of the price level in the period of repayment, real repayments are $R_{t-1} b_{t-1} / \pi_{t}$. As the second row of Table 2 displays, in the baseline calibration of our model, the volatilities of both real money balances and real government debt outstanding are four times larger than in the quasi-linear CCK model. Apparently, the Ramsey planner's ability to generate volatility in these policy instruments permits low volatility of inflation.

As the third, fourth, and fifth rows of Table 2 show, the Ramsey-optimal volatility of real money balances is sensitive to $\eta$, which governs curvature of DM preferences. To conceptually cast things in terms of a MIU model, higher values of $\eta$ mean household preferences are more risk-averse in real money holdings; a decline in volatility of $M_{t} / P_{t}$ as $\eta$ rises naturally follows. However, notice that real government debt obligations remain three to four times as volatile compared to the quasi-linear CCK model, while inflation variability remains around 0.3 percent.

The way we understand these findings, then, is that the Ramsey government essentially has two ways of engineering a particular time-path of government debt: keep real debt issuance (valued at the price level of the period of issuance) relatively state-non-contingent and then use statecontingent inflation to vary the debt returns; or make real debt issuance (valued at the price level of the period of issuance) itself somewhat state contingent, which then requires less state-contingency

\footnotetext{
${ }^{17}$ Because this result was unavailable in the literature - all results reported in the studies we have cited feature curvature in preferences with respect to leisure — we implemented a quasi-linear version of the basic CCK model ourselves.
} 
in inflation to vary the debt returns.

We view this analysis as perhaps suggesting a new way to view existing Ramsey results: what ultimately matters for the Ramsey planner is volatility in $R_{t-1} b_{t-1} / \pi_{t}$. The literature has typically understood the mechanism to be one in which the required volatility must come through $\pi_{t}$ for example, see the discussion in Chari and Kehoe (1999, p. 1741-1742). However, due to the forward-looking nature of (perhaps quite complicated) equilibrium relationships, it is conceivable that the required volatility can be engineered through variations in $b_{t}$ itself, along with the Ramsey planner's manipulation of appropriate covariances, etc., which we do not investigate. The forwardlooking nature of equilibrium relationships seems to admit this possibility. Thoroughly parsing out such effects is beyond the scope of our work; we thus leave to future research a more thorough disentangling of such effects.

\section{Conclusion}

We view our work and results as a first step in taking more seriously the new class of micro-founded models of money as a laboratory for studying policy questions. Given the general properties of the environment we study, our central findings are that the Friedman Rule is typically not the optimal policy and that inflation fluctuates very little over time. These findings are opposite those of the workhorse CCK flexible-price Ramsey model. Despite the flexibility of prices in our model, our inflation-stability result is much more in line with results from models featuring nominal rigidities than models featuring flexible prices.

In an earlier version of our work, Aruoba and Chugh (2006), we also study optimal capital taxation in the Aruoba, Waller, and Wright (2006) extension of the Lagos and Wright (2005) model. The findings we report here all carry over to the environment with capital; the main new finding is that the optimal policy calls for a subsidy to capital accumulation, counter to the standard Ramsey prescription of setting zero long-run capital taxes. In light of recent results regarding asset taxation in the new dynamic public finance literature - for example, Golosov, Kocherlakota, and Tsyvinski (2003) and Albanesi and Sleet (2006) — and Albanesi and Armenter's (2007) attempt at reconciling them with standard Ramsey results, it may be interesting to know how or whether the capital-taxation implications of a micro-founded model of monetary exchange square with this growing body of knowledge.

There are of course a number of ways one might want to modify our framework. Monopoly power in goods and labor markets are thought by many to be important realistic features. It would be straightforward to introduce monopoly power in the CM. The results of Schmitt-Grohe and Uribe (2004a) and Chugh (2006) suggest that inflation in such an environment would be partly a direct tax on the money rent we identify and partly an indirect tax on producers' and labor 
suppliers' rents. It may be interesting to know quantitatively how these direct and indirect uses of the inflation tax interact.

Once one has monopoly power in the CM, one could go further in adding elements monetary policy makers often think are important, such as nominal rigidities in prices and wages. For example, Aruoba and Schorfheide (2007) show that when one replaces the typical "cashless" assumption of a Calvo-type model with micro-founded frictions for the use of cash, welfare implications are altered significantly. Investigating both long-run and short-run optimal policy — be it monetary alone or monetary and fiscal jointly — in the presence of both temporary nominal rigidities and deep-rooted frictions underlying monetary trade also seems likely to yield new insights.

Pushing our first step in different directions, another interesting issue to study may be the nature of and solution to the time-inconsistency problem of the Ramsey policy in this sort of environment. It is not clear how the time-consistency results of, say, Alvarez, Kehoe, and Neumeyer (2004) or Persson, Persson, and Svensson (2006), would extend to our environment. Neither is it clear how the emerging results in the aforementioned new dynamic public finance literature, which places at center stage distributional concerns, might extend to a version of our environment in which money holdings were allowed to differ across households.

This paper is also part of a larger effort underway in the literature studying the policy implications of deep-rooted, non-Walrasian frictions in goods markets, money markets, and labor markets. A central focus of this larger project has been to think about what sorts of departures from typical Walrasian frameworks impinge importantly on conventional policy prescriptions derived from standard models. Much progress has recently been made using micro-founded models of labor market transactions - for example, Walsh (2005), Trigari (2006), Lubik and Krause (2007), Faia (2007), and Arseneau and Chugh (2007), to name just a few. We think much progress is in the offing using micro-founded models of money as well.

Recent developments in understanding the micro-foundations of monetary exchange are sometimes viewed as simply having provided justification for the reduced-form models of money commonly used in practice, not least of all because they superficially end up resembling the reduced-form models. Our results throw in to question the conclusion that they must therefore yield the same answers to interesting questions as existing models. We think it may be worthwhile to re-examine a number of issues in monetary policy using this now-tractable framework. 


\section{A The Ramsey Problem}

\section{A.1 Proof of Proposition 1}

That allocations from a monetary equilibrium should satisfy the CM feasibility condition (16) and the zero-lower-bound constraint (19) is obvious.

Using the household optimality conditions (12), (14), and (15) along with the equilibrium conditions, we now derive the present-value implementability constraint the Ramsey planner must respect. We begin by summing the budget constrains of the three types of agents (buyer, sellers and nonparticipants in the previous DM) to get

$$
P_{t} X_{t}+B_{t}+M_{t}=P_{t} w_{t}\left(1-\tau_{t}^{h}\right) H_{t}+M_{t-1}+R_{t-1} B_{t-1}
$$

To construct the present-value implementability constraint, begin by multiplying the flow budget constraint by $\beta^{t} U^{\prime}\left(X_{t}\right) / P_{t}$ and summing from $t=0 . . \infty$,

$$
\begin{aligned}
E_{0} & \sum_{t=0}^{\infty} \beta^{t} U^{\prime}\left(X_{t}\right) X_{t}+\sum_{t=0}^{\infty} \beta^{t} U^{\prime}\left(X_{t}\right) \frac{B_{t}}{P_{t}}+\sum_{t=0}^{\infty} \beta^{t} U^{\prime}\left(X_{t}\right) \frac{M_{t}}{P_{t}}= \\
& \sum_{t=0}^{\infty} \beta^{t} U^{\prime}\left(X_{t}\right)\left(1-\tau_{t}^{h}\right) w_{t} H_{t}+\sum_{t=0}^{\infty} \beta^{t} U^{\prime}\left(X_{t}\right) \frac{M_{t-1}}{P_{t}}+\sum_{t=0}^{\infty} \beta^{t} U^{\prime}\left(X_{t}\right) \frac{R_{t-1} B_{t-1}}{P_{t}} .
\end{aligned}
$$

We point out that, as usual in a dynamic Ramsey problem assuming commitment to the timezero policy, any $E_{t}$ terms that appear in intermediate expressions are eliminated by the law of iterated expectations because the entire implementability constraint is conditioned on the timezero information set, hence the $E_{0}$. For ease of exposition, we therefore proceed dropping $E_{t}$ operators that would appear in intermediate expressions as well as the $E_{0}$ operator because it is understood to be present in all subsequent expressions.

Substitute into the second term on the left-hand-side using expression (15) to get

$$
\begin{aligned}
& \sum_{t=0}^{\infty} \beta^{t} U^{\prime}\left(X_{t}\right) X_{t}+\sum_{t=0}^{\infty} \beta^{t+1} U^{\prime}\left(x_{t+1}\right) \frac{R_{t} B_{t}}{P_{t+1}}+\sum_{t=0}^{\infty} \beta^{t} U^{\prime}\left(X_{t}\right) \frac{M_{t}}{P_{t}}= \\
& \quad \sum_{t=0}^{\infty} \beta^{t} U^{\prime}\left(X_{t}\right)\left(1-\tau_{t}^{h}\right) w_{t} H_{t}+\sum_{t=0}^{\infty} \beta^{t} U^{\prime}\left(X_{t}\right) \frac{M_{t-1}}{P_{t}}+\sum_{t=0}^{\infty} \beta^{t} U^{\prime}\left(X_{t}\right) \frac{R_{t-1} B_{t-1}}{P_{t}} .
\end{aligned}
$$

The second summation on the left-hand-side cancels with the the last summation on the righthand-side to leave only the initial bond position,

$\sum_{t=0}^{\infty} \beta^{t} U^{\prime}\left(X_{t}\right) X_{t}+\sum_{t=0}^{\infty} \beta^{t} U^{\prime}\left(X_{t}\right) \frac{M_{t}}{P_{t}}=\sum_{t=0}^{\infty} \beta^{t} U^{\prime}\left(X_{t}\right)\left(1-\tau_{t}^{h}\right) w_{t} H_{t}+\sum_{t=0}^{\infty} \beta^{t} U^{\prime}\left(X_{t}\right) \frac{M_{t-1}}{P_{t}}+U^{\prime}\left(x_{0}\right) \frac{R_{-1} B_{-1}}{P_{0}}$. 
Next, substitute into the second term on the left-hand-side using (14) to get

$$
\begin{aligned}
& \sum_{t=0}^{\infty} \beta^{t} U^{\prime}\left(X_{t}\right) X_{t}+\sum_{t=0}^{\infty} \beta^{t+1} U^{\prime}\left(x_{t+1}\right) \frac{M_{t}}{P_{t+1}}\left[\sigma \frac{u^{\prime}\left(q_{t}\right)}{g^{\prime}\left(q_{t}\right)}+1-\sigma\right]= \\
& \sum_{t=0}^{\infty} \beta^{t} U^{\prime}\left(X_{t}\right)\left(1-\tau_{t}^{h}\right) w_{t} H_{t}+\sum_{t=0}^{\infty} \beta^{t} U^{\prime}\left(X_{t}\right) \frac{M_{t-1}}{P_{t}}+U^{\prime}\left(x_{0}\right) \frac{R_{-1} B_{-1}}{P_{0}} .
\end{aligned}
$$

Expand the second summation on the left-hand-side to get

$$
\begin{gathered}
\sum_{t=0}^{\infty} \beta^{t} U^{\prime}\left(X_{t}\right) X_{t}+\sum_{t=0}^{\infty} \beta^{t+1} U^{\prime}\left(x_{t+1}\right) \frac{M_{t}}{P_{t+1}}+\sigma \sum_{t=0}^{\infty} \beta^{t+1} U^{\prime}\left(x_{t+1}\right) \frac{M_{t}}{P_{t+1}}\left[\frac{u^{\prime}\left(q_{t}\right)}{g^{\prime}\left(q_{t}\right)}-1\right] \\
=\sum_{t=0}^{\infty} \beta^{t} U^{\prime}\left(X_{t}\right)\left(1-\tau_{t}^{h}\right) w_{t} H_{t}+\sum_{t=0}^{\infty} \beta^{t} U^{\prime}\left(X_{t}\right) \frac{M_{t-1}}{P_{t}}+U^{\prime}\left(x_{0}\right) \frac{R_{-1} B_{-1}}{P_{0}} .
\end{gathered}
$$

Cancel the second summation on the left-hand-side with the second summation on the right-handside to leave only the initial money holdings,

$\sum_{t=0}^{\infty} \beta^{t} U^{\prime}\left(X_{t}\right) X_{t}+\sigma \sum_{t=0}^{\infty} \beta^{t+1} U^{\prime}\left(x_{t+1}\right) \frac{M_{t}}{P_{t+1}}\left[\frac{u^{\prime}\left(q_{t}\right)}{g^{\prime}\left(q_{t}\right)}-1\right]=\sum_{t=0}^{\infty} \beta^{t} U^{\prime}\left(X_{t}\right)\left(1-\tau_{t}^{h}\right) w_{t} H_{t}+U^{\prime}\left(x_{0}\right)\left[\frac{M_{-1}+R_{-1} B_{-1}}{P_{0}}\right]$.

Using (12), we can substitute into the first term on the right-hand-side to get

$\sum_{t=0}^{\infty} \beta^{t} U^{\prime}\left(X_{t}\right) X_{t}-\sum_{t=0}^{\infty} \beta^{t} A H_{t}+\sigma \sum_{t=0}^{\infty} \beta^{t+1} U^{\prime}\left(x_{t+1}\right) \frac{M_{t}}{P_{t+1}}\left[\frac{u^{\prime}\left(q_{t}\right)}{g_{q}\left(q_{t}, Z_{t}\right)}-1\right]=U^{\prime}\left(x_{0}\right)\left[\frac{M_{-1}+R_{-1} B_{-1}}{P_{0}}\right]$.

Writing $\frac{M_{t}}{P_{t+1}}=\frac{M_{t}}{P_{t}} \frac{P_{t}}{P_{t+1}}$, express this as

$\sum_{t=0}^{\infty} \beta^{t} U^{\prime}\left(X_{t}\right) X_{t}-\sum_{t=0}^{\infty} \beta^{t} A H_{t}+\sigma \sum_{t=0}^{\infty} \beta^{t+1} U^{\prime}\left(x_{t+1}\right) \frac{M_{t}}{P_{t}} \frac{P_{t}}{P_{t+1}}\left[\frac{u^{\prime}\left(q_{t}\right)}{g_{q}\left(q_{t}, Z_{t}\right)}-1\right]=U^{\prime}\left(x_{0}\right)\left[\frac{M_{-1}+R_{-1} B_{-1}}{P_{0}}\right]$.

Use (18) to substitute for $M_{t} / P_{t}$,

$$
\begin{gathered}
\sum_{t=0}^{\infty} \beta^{t} U^{\prime}\left(X_{t}\right) X_{t}-\sum_{t=0}^{\infty} \beta^{t} A H_{t}+\sigma \sum_{t=0}^{\infty} \beta^{t+1} \frac{U^{\prime}\left(x_{t+1}\right)}{P_{t+1}} \frac{P_{t}}{U^{\prime}\left(X_{t}\right)} g\left(q_{t}, Z_{t}\right)\left[\sigma \frac{u^{\prime}\left(q_{t}\right)}{g_{q}\left(q_{t}, Z_{t}\right)}+1-\sigma\right]\left[\frac{u^{\prime}\left(q_{t}\right)}{g_{q}\left(q_{t}, Z_{t}\right)}-1\right] \\
=U^{\prime}\left(x_{0}\right)\left[\frac{M_{-1}+R_{-1} B_{-1}}{P_{0}}\right] .
\end{gathered}
$$

Finally, from (14), we can make the substitution $\beta E_{t}\left[\frac{U^{\prime}\left(x_{t+1}\right)}{P_{t+1}}\right]=\frac{U^{\prime}\left(X_{t}\right)}{P_{t}}\left[\sigma \frac{u^{\prime}\left(q_{t}\right)}{g_{q}\left(q_{t}, Z_{t}\right)}+1-\sigma\right]^{-1}$ in the third summation on the left-hand-side. Cancelling terms and reintroducing the $E_{0}$ operator leaves us with

$$
E_{0} \sum_{t=0}^{\infty} \beta^{t}\left[U^{\prime}\left(X_{t}\right) X_{t}-A H_{t}+\sigma g\left(q_{t}, Z_{t}\right)\left(\frac{u^{\prime}\left(q_{t}\right)}{g_{q}\left(q_{t}, Z_{t}\right)}-1\right)\right]=U^{\prime}\left(x_{0}\right)\left[\frac{M_{-1}+R_{-1} B_{-1}}{P_{0}}\right]
$$

which is the present-value implementability (PVIC) constraint for the Ramsey problem in the LW model. Any allocation that satisfies this restriction, the resource constraint, and the ZLB constraint can be supported as a monetary equilibrium; furthermore, the allocations from any monetary equilibrium can be described by these three conditions. 


\section{A.2 The Solution to the Ramsey Problem}

The Kuhn-Tucker conditions for the problem in Section 3 are

$$
\begin{gathered}
{\left[u^{\prime}\left(q_{t}\right)-c_{q}\left(q_{t}, Z_{t}\right)\right]} \\
+\xi\left[g_{q}\left(q_{t}, Z_{t}\right)\left(\frac{u^{\prime}\left(q_{t}\right)}{g_{q}\left(q_{t}, Z_{t}\right)}-1\right)+g\left(q_{t}, Z_{t}\right)\left(\frac{u^{\prime \prime}\left(q_{t}\right) g_{q}\left(q_{t}, Z_{t}\right)-u^{\prime}\left(q_{t}\right) g_{q q}\left(q_{t}, Z_{t}\right)}{\left[g_{q}\left(q_{t}, Z_{t}\right)\right]^{2}}\right)\right] \\
+\iota_{t}\left[\frac{u^{\prime \prime}\left(q_{t}\right) g_{q}\left(q_{t}, Z_{t}\right)-u^{\prime}\left(q_{t}\right) g_{q} q\left(q_{t}, Z_{t}\right)}{g_{q}\left(q_{t}, Z_{t}\right)^{2}}\right]=0 \\
U^{\prime}\left(X_{t}\right)-\frac{A}{Z_{t}}+\xi\left[U^{\prime \prime}\left(X_{t}\right) X_{t}+U^{\prime}\left(X_{t}\right)-\frac{A}{Z_{t}}\right]=0 \\
E_{0} \sum_{t=0}^{\infty} \beta^{t}\left[U^{\prime}\left(X_{t}\right) X_{t}-A H_{t}+\sigma g\left(q_{t}, Z_{t}\right)\left(\frac{u^{\prime}\left(q_{t}\right)}{g_{q}\left(q_{t}, Z_{t}\right)}-1\right)\right]=Z_{t}\left(x_{0}\right)\left[\frac{M_{-1}+R_{-1} B_{-1}}{P_{0}}\right] \\
\iota_{t}\left[\frac{u^{\prime}\left(q_{t}\right)}{g_{q}\left(q_{t}, Z_{t}\right)}-1\right]=0, \text { and } \iota_{t} \geq 0
\end{gathered}
$$

We can represent the right-hand side of the PVIC in terms of allocations as

$$
U^{\prime}(X)\left[\frac{g(q, 1)}{\beta U^{\prime}(X)}+\frac{\mathcal{B}}{\beta}\right]
$$

where $\mathcal{B}$ is the steady state real bond balances and variables without subscripts are steady state values.

With these FOCs in hand, we proceed as follows. Imposing steady state on these conditions, we solve for the steady state values of allocations and the multiplier $\xi$. Next, given $\xi$ and $\left\{Z_{t}, G_{t}\right\}$, the conditions above characterize $\left\{q_{t}, X_{t}, \iota_{t}\right\}$ and (16) defines $\left\{H_{t}\right\}$. Finally, we back out policies $\left\{\tau_{t}^{h}, R_{t}\right\}$ from (12) and (17) statically, and inflation can be obtained from solving (14) dynamically. 


\section{References}

Albanesi, Stefania and Christopher Sleet. 2006. "Dynamic Optimal Taxation with Private Information." Review of Economic Studies, Vol. 73, pp. 1-30.

Albanesi, Stefania And Roc Armenter. 2007. "Intertemporal Distortions in the Second Best." Columbia University.

Alvarez, Fernando, Patrick J. Kehoe, and Pablo Andres Neumeyer. 2004. "The Time Consistency of Optimal Monetary and Fiscal Policies." Econometrica, Vol. 72, pp. 541-567.

Arseneau, David M. and Sanjay K. Chugh. 2007. "Optimal Fiscal and Monetary Policy with Costly Wage Bargaining." International Finance Discussion Paper no. 893 , Board of Governors of the Federal Reserve System.

Aruoba, S. Boragan and Sanjay K. Chugh. 2006. "Optimal Fiscal and Monetary Policy When Money is Essential." International Finance Discussion Paper no. 880 , Board of Governors of the Federal Reserve System.

Aruoba, S. Boragan, Jesus Fernandez-Villaverde, and Juan F. Rubio-Ramirez. 2006. "Comparing Solution Methods for Dynamic Equilibrium Economies." Journal of Economic Dynamics and Control, Vol. 30(12), pp. 2477-2508.

Aruoba, S. Boragan, Guillaume Rocheteau, and Christoper J. Waller. 2007. "Bargaining and the Value of Money." Journal of Monetary Economics. Forthcoming.

Aruoba, S. Boragan, Christoper J. Waller, and Randall Wright. 2006. "Money and Capital." University of Maryland.

Aruoba, S. Boragan and Frank Schhorfheide. 2007. "Insights from an Estimated SearchBased Monetary Model with Nominal Rigidities." University of Maryland.

Atkinson, Anthony B. And Joseph E. Stiglitz. 1980. Lectures on Public Economics. New York: McGraw Hill.

Barro, Robert J. 1979. "On the Determination of the Public Debt." Journal of Political Economy, Vol. 87, pp. 940-971.

Bhattacharya, J., J. Haslag, and Antoine Martin. 2005. "Heterogeneity, Redistribution, and the Friedman Rule." International Economic Review, Vol. 46, pp. 437-454.

Chari, V.V., Lawrence Christiano, and Patrick Kehoe. 1991. "Optimal Fiscal and Monetary Policy: Some Recent Results." Journal of Money, Credit, and Banking, Vol. 23, pp. 519-539.

Chari V. V., and Patrick J. Kehoe. 1999. "Optimal Fiscal and Monetary Policy. In Handbook of Macroeconomics, edited by John B. Taylor and Michael Woodford, Vol. 1C. Elsevier.

Chugh, Sanjay K. 2006. "Optimal Fiscal and Monetary Policy with Sticky Wages and Sticky 
Prices." Review of Economic Dynamics, Vol. 9, pp. 683-714.

Chugh, Sanjay K. 2007. "Optimal Inflation Persistence: Ramsey Taxation with Capital and Habits." Journal of Monetary Economics, Vol. 54, pp. 1809-1836.

Correia, Isabel, Juan Pablo Nicolini, and Pedro Teles. 2002. "Optimal Fiscal and Monetary Policy: Equivalence Results." Federal Reserve Bank of Chicago.

FAiA, Ester. 2007. "Optimal Monetary Policy Rules with Labor Market Frictions." Journal Economic Dynamics and Control. Forthcoming.

Golosov, Mikhail, Narayana Kocherlakota, and Aleh Tsyvinski. 2003. "Optimal Indirect and Capital Taxation." Review of Economic Studies, Vol. 70, pp. 569-588.

Head, Allan and Alok Kumar. 2005. "Price Dispersion, Inflation, and Welfare." International Economic Review, Vol. 46, pp. 533-572.

Howitt, Peter. 2003. "Comment On: Search, Money, and Capital: A Neoclassical Dichotomy." Journal of Money, Credit, and Banking, Vol. 35, pp. 1107-1110

Judd, Kenneth L. 1992. "Projection Methods for Solving Aggregate Growth Models." Journal of Economic Theory, Vol. 58, pp. 410-452

Khan, Aubhik, Robert G. King and Alexander L. Wolman. 2003. "Optimal Monetary Policy." Review of Economic Studies, Vol. 70, pp. 825-860.

Kiyotaki, Nobuhiro and Randall Wright. 1989. "On Money As a Medium of Exchange." Journal of Political Economy, Vol. 97, pp. 927-954.

Kiyotaki, Nobuhiro and Randall Wright. 1993. "A Search-Theoretic Approach to Monetary Economics." American Economic Review, Vol. 83, pp. 63-77.

Kocherlakota, Narayana R. 1998. "Money is Memory." Journal of Economic Theory, Vol. 81, pp. 232-251.

Kocherlakota, Narayana R. 2005. "Optimal Monetary Policy: What We Know and What We Don’t Know." Federal Reserve Bank of Minneapolis Quarterly Review, Vol. 29, pp. 10-19.

Krause, Michael U. and Thomas A. Lubik. 2007. "The (Ir)relevance of Real Wage Rigidity in the New Keynesian Model with Search Frictions." Journal of Monetary Economics, Vol. 54, pp. 706-727.

Lagos, Ricardo and Randall Wright. 2005. "A Unified Framework for Monetary Theory and Policy Analysis." Journal of Political Economy, Vol. 113, pp. 463-484.

Lucas, Robert E. Jr. and Nancy L. Stokey. 1983. "Optimal Fiscal and Monetary Policy in an Economy Without Capital." Journal of Monetary Economics, Vol. 12, pp. 55-93.

Persson, Mats, Torsten Persson, and Lars E. O. Svensson. 2006. "Time Consistency of Fiscal and Monetary Policy: A Solution.” Econometrica, Vol. 74, pp. 193-212.

Rocheteau, Guillaume and Randall Wright. 2005. "Money in Search equilibrium, in 
Competitive Equilibrium, and in Competitive Search Equilibrium." Econometrica, Vol. 73, pp. 175-202.

Schmitt-Grohe, Stephanie and Martin Uribe. 2004a. "Optimal Fiscal and Monetary Policy Under Imperfect Competition.” Journal of Macroeconomics, Vol. 26, pp. 183-209.

Schmitt-Grohe, Stephanie and Martin Uribe. 2004b. "Optimal Fiscal and Monetary Policy Under Sticky Prices." Journal of Economic Theory, Vol. 114, pp. 198-230.

Shi, Shouyong. 1997. "A Divisible Search Model of Fiat Money." Econometrica, Vol. 65, pp. $75-102$.

Siu, Henry E. 2004. "Optimal Fiscal and Monetary Policy with Sticky Prices." Journal of Monetary Economics, Vol. 51, pp. 576-607.

Trigari, Antonella. 2006. "The Role of Search Frictions and Bargaining for Inflation Dynamics." Bocconi University.

Walsh, Carl E. 2005. " "Labor Market Search, Sticky Prices, and Interest Rate Policies." Review of Economic Dynamics, Vol. 8, pp. 829-849. 


\section{Figure 1 - Ramsey Steady-State in the Basic Model}
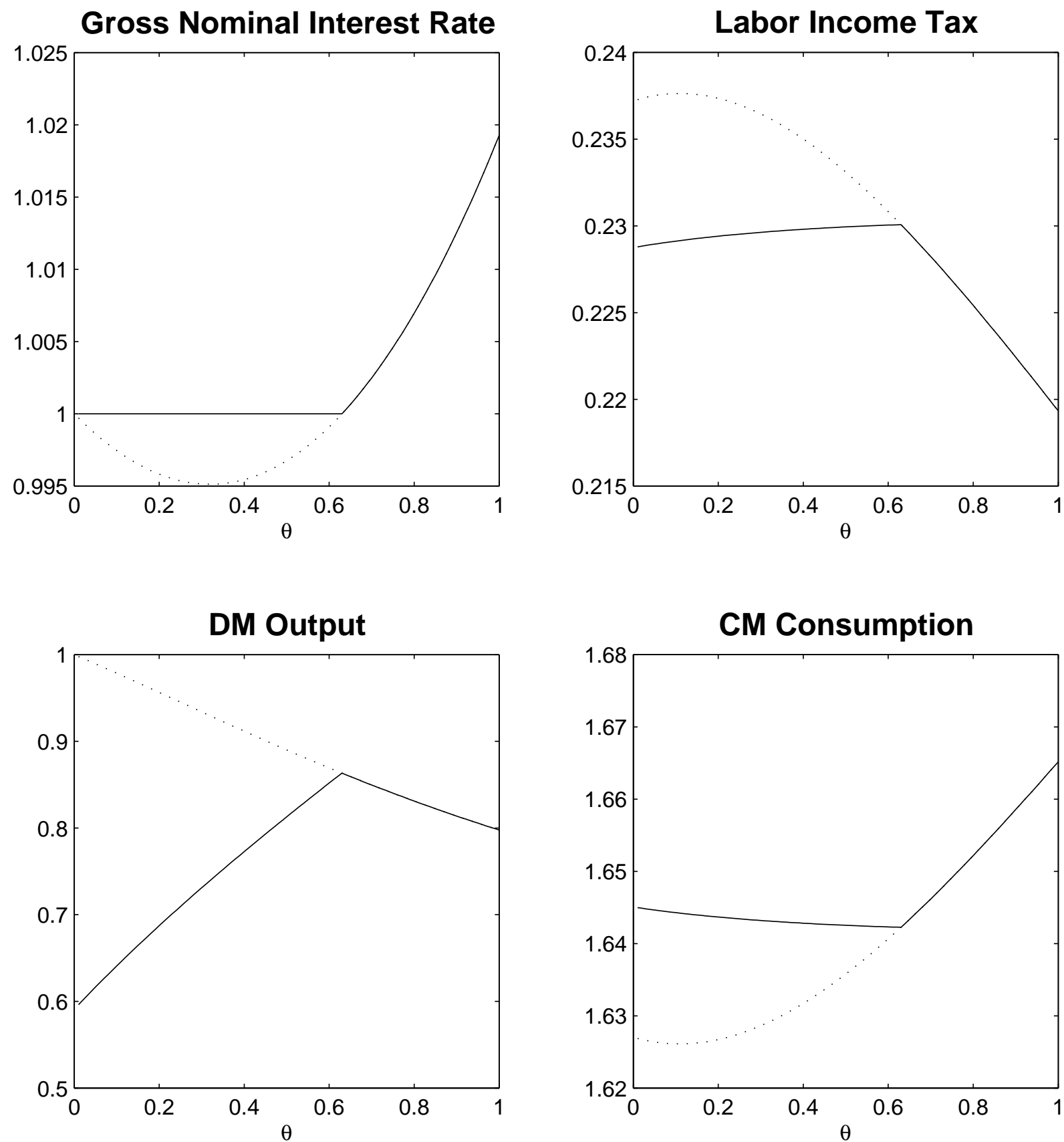

Notes : Ramsey steady-state policy and allocation as a function of $\theta$ with the ZLB constraint (solid line) and without the ZLB constraint (dotted line). 


\section{Table 1 - Simulation Results}

(a) Price-Taking / Bargaining $(\theta=1)$

\begin{tabular}{lrrrrrr}
\hline \hline Variable & Mean & Std. Dev. & Auto corr. & Corr $(x, Y)$ & Corr $(x, Z)$ & $\operatorname{Corr}(x, G)$ \\
\hline$\pi-1$ & -1.987 & 0.240 & 0.805 & 0.722 & 0.999 & 0.005 \\
$\tau^{h}$ & 0.220 & 0 & - & - & - & - \\
$R-1$ & 1.931 & 0 & - & - & - & - \\
$q$ & 0.798 & 0.036 & 0.806 & 0.723 & 1.000 & 0.005 \\
$X$ & 1.664 & 0.020 & 0.806 & 0.723 & 1.000 & 0.005 \\
$H$ & 2.065 & 0.028 & 0.874 & 0.554 & -0.167 & 0.985 \\
$G D P$ & 2.263 & 0.040 & 0.840 & 1 & 0.723 & 0.689 \\
$P_{D M} / P$ & 0.795 & 0 & - & - & - & - \\
\hline
\end{tabular}

(b) Bargaining $(\theta<1)$

\begin{tabular}{lrrrrrr}
\hline \hline Variable & Mean & Std. Dev. & Auto corr. & $\operatorname{Corr}(x, G D P)$ & $\operatorname{Corr}(x, Z)$ & $\operatorname{Corr}(x, G)$ \\
\hline$\pi-1$ & -3.844 & 0.236 & 0.805 & 0.681 & 0.999 & 0.005 \\
$\tau^{h}$ & 0.277 & 0 & - & - & - & - \\
$R-1$ & 0 & 0 & - & - & - & - \\
$q$ & 0.573 & 0.017 & 0.806 & 0.683 & 1.000 & 0.005 \\
$X$ & 1.287 & 0.015 & 0.806 & 0.683 & 1.000 & 0.005 \\
$H$ & 1.688 & 0.028 & 0.874 & 0.600 & -0.166 & 0.985 \\
$G D P$ & 2.024 & 0.038 & 0.844 & 1 & 0.683 & 0.729 \\
$P_{D M} / P$ & 1.173 & 0 & - & - & - & - \\
\hline
\end{tabular}

Notes: Simulation-based moments. Inflation and nominal interest rate reported in percentage points. 


\section{Table 2 - Volatility of Ramsey Policies and Allocations}

\begin{tabular}{lrrrrr|r}
\hline \hline Model & $M_{t} / P_{t}$ & $B_{t-1} / P_{t-1}$ & $G D P_{t}$ & $H_{t}$ & $\pi_{t}$ & Long-run $\pi$ \\
\hline CCK, quasi-linear preferences & 1.03 & 0.008 & 2.18 & 1.13 & 3.240 & -3.97 \\
Baseline model $(\eta=0.27)$ & 4.45 & 0.032 & 1.78 & 1.39 & 0.265 & -2.20 \\
Model with $\eta=1$ & 1.18 & 0.026 & 1.57 & 1.37 & 0.277 & 2.60 \\
Model with $\eta=2$ & 0.59 & 0.026 & 1.51 & 1.33 & 0.294 & 9.10 \\
Model with $\eta=5$ & 0.24 & 0.027 & 1.42 & 1.26 & 0.330 & 22.0 \\
\hline
\end{tabular}

Notes: Simulation-based volatilities of key Ramsey policy and allocation variables. All volatilities reported in terms of percentage standard deviations, except end-of-period bond obligations and inflation, which are reported as absolute standard deviations. Inflation statistics reported in percentage points. 